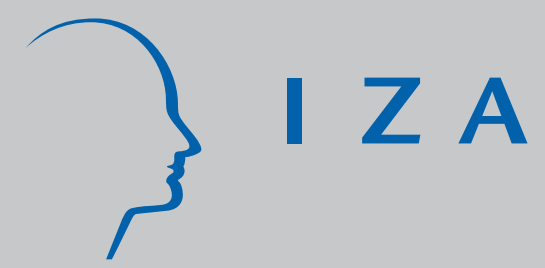

IZA DP No. 7602

Motivating Agents: How Much Does the Mission Matter?

Jeffrey Carpenter

Erick Gong

August 2013

Forschungsinstitut zur Zukunft der Arbeit Institute for the Study of Labor 


\title{
Motivating Agents: How Much Does the Mission Matter?
}

\author{
Jeffrey Carpenter \\ Middlebury College \\ and IZA
}

Erick Gong

Middlebury College

\section{Discussion Paper No. 7602 \\ August 2013}

\author{
IZA \\ P.O. Box 7240 \\ 53072 Bonn \\ Germany
}

Phone: +49-228-3894-0

Fax: +49-228-3894-180

E-mail: iza@iza.org

Any opinions expressed here are those of the author(s) and not those of IZA. Research published in this series may include views on policy, but the institute itself takes no institutional policy positions. The IZA research network is committed to the IZA Guiding Principles of Research Integrity.

The Institute for the Study of Labor (IZA) in Bonn is a local and virtual international research center and a place of communication between science, politics and business. IZA is an independent nonprofit organization supported by Deutsche Post Foundation. The center is associated with the University of Bonn and offers a stimulating research environment through its international network, workshops and conferences, data service, project support, research visits and doctoral program. IZA engages in (i) original and internationally competitive research in all fields of labor economics, (ii) development of policy concepts, and (iii) dissemination of research results and concepts to the interested public.

IZA Discussion Papers often represent preliminary work and are circulated to encourage discussion. Citation of such a paper should account for its provisional character. A revised version may be available directly from the author. 


\title{
ABSTRACT
}

\section{Motivating Agents: How Much Does the Mission Matter?}

\begin{abstract}
Economic theory predicts that agents will work harder if they believe in the "mission" of the organization. Well-identified estimates of exactly how much harder they will work have been elusive, however, because agents select into jobs. We conduct a real effort experiment with participants who work directly for organizations with clear missions. Weeks before the experiment, we survey potential participants for their organizational preferences. At the experiment, we randomly assign workers to organizations, creating either mission matches or mismatches. We overlay performance incentives to test whether they can make up for the motivational deficit caused by a mismatch. Our estimates suggest that matched workers produce $72 \%$ more than mismatched workers and that performance pay can increase output by $35 \%$ compared to workers who only receive a base wage. Considering matches and mismatches separately, we find that performance pay has only a modest effect on matched workers (a 13\% increase) while it has a large effect (a 86\% increase) on mismatches, an effect that erodes much of the performance gap caused by the poor match. Our results have broad implications both for those organizations already with well-defined missions (i.e., compensation and screening policies) as well as for those organizations strategizing about strengthening or clarifying their missions.
\end{abstract}

\section{NON-TECHNICAL SUMMARY}

How much harder do people work when they believe in the mission of their organization? Perhaps as important, how much less do they work when they disagree with the mission? We conduct an experiment to estimate the effect of missions on worker productivity. During the 2012 US Presidential election, we randomly assign individuals to work for either the Obama or Romney presidential campaigns thus creating both mission "matches" and "mismatches." Compared to people who do not care intensely about the candidates, we find that matched Democrats or Republicans assigned to work for their preferred candidate have a $27 \%$ increase in productivity but mismatched workers assigned to work for the other candidate work $43 \%$ less. We also find, however, that workers who were assigned to work for their opposition could be "bought" - performance-based incentives for these workers greatly mitigate the productivity gap. This work has implications for how organizations define their mission, screen workers, and provide compensation.

JEL Classification: $\quad$ C91, J22, J33, M52

Keywords: principal-agent, mission, incentive, labor supply, experiment

Corresponding author:

Jeffrey Carpenter

Department of Economics

Middlebury College

Middlebury, VT 05753

USA

E-mail: jpc@middlebury.edu 


\section{Introduction}

Organizations, both for- and not-for-profit, have embraced the notion of having a mission. Mission statements are seen as a way to clarify (and perhaps advertise) the role the organization sees itself fulfilling in society. However, they may also be a way to attract workers whose enthusiasm for the mission translates into higher job satisfaction and greater effort. The Gallup Corporation polled workers in the United States and found that employees who felt their job was important due to their employer's mission were more engaged and productive (Ellingwood, 2001, Harter et al., 2006). While this result comes as no surprise to many, given the underlying selection process, it is actually quite hard to identify the pure effect of a "mission match." Controlling for sorting, exactly how much more productive are workers who believe in the organization's mission?

Although well-matched workers may be a boon for any organization, during tight labor markets it is unlikely that all workers sort perfectly into organizations based on their mission preferences. Workers without alternatives may join organizations with little regard to the mission. As the Gallup poll also found, workers who are unmotivated by the organization's mission are more than four times less likely to believe that they are paid fairly. In the case of these mismatches, can increases in traditional financial incentives make up the motivational deficit? If pay is linked to performance, will even "mismatched" employees work hard?

Neither of these questions has been completely addressed in the empirical literature, but the idea that worker preferences for an organization's mission can lead to sorting, screening and higher effort has been addressed conceptually. Francois (2000) was an early theoretical contribution that showed that "public service motivation" could lead workers to provide more effort, even in organizations with low-powered financial incentives. Akerlof and Kranton (2005) focus on the motivational importance of "identity" and conclude that employers who can align worker identities with the mission goals of the organization can benefit from hard working employees, again even with "low-powered" incentives that do not link pay to performance.

The contribution that directly motivates our study is Besley and Ghatak (2005). Here, focusing on "mission-oriented" workers, the authors show that when workers are matched to organizations with which they share a common mission, financial and mission preferences are substitutes. While matched workers will work hard for the 
mission often despite little financial incentive to do so, to elicit effort from mismatched workers (or those who are just uninspired by the mission), organizations must rely on "high-powered" incentives (e.g., piece rates or commissions). While the existing literature has focused, almost exclusively, on how mission preferences can be used to screen and sort workers (see Dur and Zoutenbier, 2012 or Banuri and Keefer, 2013), we focus on estimating the motivational effect of mission match on effort, an effect that does not have to be filtered through the process of employment selection.

A challenge in identifying the effects of mission match (and mismatch) is that worker mission preferences may be difficult to measure. In addition, organizations' mission statements may be ambiguous, not well known, or both. To circumvent these issues, we took advantage of the 2012 presidential election in the United States to provide an experimental setting in which missions, and preferences for missions, were particularly well-formed. Both major party campaigns spent millions of dollars advertising their beliefs and platforms; hence the mission of each campaign was well known. We also decided to take advantage of the election because of our interest in mismatches. Had we chosen to ask participants to work for an organization like the American Cancer Society, it would have been difficult, if not impossible, to create mismatches - no one would disagree with the mission.

We first measured both the political preferences and the intensity of those preferences of potential study participants weeks prior to the experiment. At each experimental session, we randomly assigned participants to work directly for one of the two major party campaigns. Participants identified as Democrats (Republicans) who were assigned to work for Obama (Romney) are considered matches in our analysis and the rest are classified as mismatches. The campaign work involved a real effort task that campaign volunteers routinely perform: stuffing and addressing letters to independent voters in Ohio (an important swing state). We find a large effect of the match on productivity (i.e., the number of campaign letters completed). Matched workers produce $72 \%$ more output than mismatched workers and this result is driven by changes in both the worker's choice to work and how hard they work, conditional on participating.

To assess whether incentives are substitutes for missions, we overlaid our matches with high-powered incentives. We randomly offered participants either a fixed base wage, or the base wage plus piece-rate incentives of $\$ 0.50$ or $\$ 1.00$ per completed letter. Not surprisingly, we find incentives increase output significantly, 35\% on average. 
What is most important, however, is that the incentives have a much stronger effect on mismatched workers. The piece-rate incentives increase productivity a modest $13 \%$ for matched workers, but this effect is dwarfed by the $86 \%$ increase seen among the mismatches. In fact, these high-powered incentives can make up more than two-thirds of the productivity lost due to a poor match. These results suggest that high-powered incentives can substitute (albeit imperfectly) for mission alignment.

Our study contributes to the nascent literature estimating the implications of organizations having clear missions. In a chosen effort lab environment, Fehrler and Kosfeld (2012) find an increase in effort among mission-motivated workers only once firms can screen workers by offering less financially attractive contracts. If screening is not possible, participants still chose higher efforts when doing so ultimately benefits a charity but the increment is not significant. This finding resembles Tonin and Vlassopoulos $(2010,2012)$ who conduct real effort experiments on-line and find small mission effort premia which are driven to a large extent by female participants. In another chosen effort experiment Gerhards (2012) finds that mission-motivated agents work harder but that principals fail to realize that they can reduce their monetary incentives once they have attracted mission-motivated workers. A key difference between these studies and ours is our study utilizes a real effort task that is directly tied to the success of the organization. Instead of asking participants to donate a portion of their earnings to a charity like previous experiments, our design is distinctive because participants were asked to expend effort directly for the mission. Our workers produce tangible output that unambiguously helps advance the mission of the organization. ${ }^{1}$

Our results have implications for human resource policies at many organizations, those with clear missions and those that seek to clarify their missions. First, we determine that although matches help average productivity considerably, it is mismatches that may have the largest implications for the performance of an organization. Using our measure of a worker's intensity of preferences, we generate a group that is relatively unmotivated by missions and find that matching increases productivity $23 \%$ compared to this "no-match" group while mismatched workers produced $43 \%$ less than the no-matches. As a result, the productivity gap between matched and mismatched

\footnotetext{
${ }^{1}$ Besley and Ghatak (2005) note that, "donating our income earned in the market to an organization that pursues a mission that we care about is likely to be an imperfect substitute for joining and working in it," a hypothesis recently confirmed in Brown et al. (2013).
} 
workers is cavernous and the lesson is clear - while agents sorting on the mission can help an organization substantially, not screening to prevent mismatches might hurt productivity even more. Second, for those organizations that might have a hard time screening workers based on their mission preferences, there is some good news, at least for those organizations that have relatively deep pockets. It does appear that workers respond to high-powered financial incentives, especially those who are mismatched. Third, we find no evidence that incentives crowd-out intrinsic motivation due to mission matching; while incentives have a much more muted effect for

those who are matched, there is still some incremental increase in productivity when matched workers receive incentives.

We proceed in the next section by presenting a conceptual framework that makes explicit our hypotheses about how mission match, the intensity of one's mission preferences and financial incentives should affect participation and effort. This simple model also dictated our study design and the data that we collected. In the third section we discuss our empirical strategy in detail, including our design choices, the method of mission preference elicitation that we used, and our real effort experiment. We then describe our results in sections four and five. We offer a few concluding remarks in the final section.

\section{Conceptual Framework}

We develop a simple framework to examine the effects that both mission matching and pecuniary incentives have on a worker's productivity. We use the standard principalagent paradigm, where the principal offers a wage contract and the agent (worker) decides how much effort, $e$, to exert. A formal exposition can be found in Appendix A.1. Below we summarize the key intuition and predictions.

The agent receives both a fixed wage $(w)$ and a performance incentive $(p)$, so assuming effort and output are synonymous, the agent's standard linear contract entitles her to $w+p e$. As is also standard, agent effort is both costly $\left(C(e) ; C_{e}>0\right)$ and increasingly so $\left(C_{e e}>0\right)$.

Motivated by Besley and Ghatak (2005), agents with "mission preferences" receive utility increments from two sources if they work for the right principal (i.e., one engaged in the agent's preferred mission). First, just exerting effort for one's preferred mission increases utility $M(e)$ and $M_{e}>0$, but the process exhibits diminishing 
returns $M_{e e}<0$. Second, we allow for differences in the intensity of agent mission preferences, denoted $\gamma$. In this case, agents who believe more strongly in the mission supported by the principal will also receive more utility $\left(M(\gamma) ; M_{\gamma}>0\right)$ but this effect diminishes too (i.e., $M_{\gamma \gamma}<0$ ). We assume that our framework subsumes the standard principal-agent model when $\gamma=0$. That is, $M(e, \gamma)=0$ if $\gamma=0$. Lastly, we assume some interaction between these two forces: diminishing returns to effort set in later for those agents with more intense mission preferences (i.e., $M_{e \gamma}>0$ ).

Because not all principal-agent dyads will be characterized by a common mission, we use $\theta \in\{-1,1\}$ to separate matches, $\theta=1$, when an agent's mission preferences align with the principal, from mismatches, $\theta=-1$, when an agent has mission preferences that are at odds with the principal's. In other words, while our matched workers enjoy providing effort to some degree, our mismatches find work even more onerous because they are working for the wrong cause. Putting this altogether, our agent's mission utility is summarized as $\theta M(e, \gamma)$. If helpful, one can think of $\theta M(e, \gamma)$ as either attenuating the cost of effort when the agent is well-matched with the principal's mission or adding to it when the agent is mismatched.

The agent, therefore, chooses an effort level $e^{*}$ that maximizes the utility function:

$$
U(e)=(w+p e)+\theta M(e, \gamma)-C(e)
$$

and the first-order condition, $p+\theta M_{e}=C_{e}$, highlights that both the piece-rate $(p)$ and mission matching $(\theta)$ will determine an agent's level of effort.

Our agents also have outside options that generate reservation utilities, $\bar{U}$. We assume a continuous distribution of reservation utilities, and that principals do not know an agent's reservation utility before making a wage offer. Since our focus is on the agent, we allow principals to make a single contract offer, and the agent will work if $U\left(e^{*}\right)>\bar{U}$, i.e., when the familiar participation constraint is satisfied.

We first examine the effects of mission matching. The impact on effort is clear from $(1)$. For any offered contract $(w, p)$, an agent exerts greater effort when matched compared to when mismatched $e_{\theta=1}^{*}>e_{\theta=-1}^{*}$. Because matching results in greater utility $U\left(e_{\theta=1}^{*}\right)>U\left(e_{\theta=-1}^{*}\right)$, it must also be the case that matches are more likely to satisfy the participation constraint. Matching should thus affect both the intensive margin (increasing $e^{*}$ ) and the extensive margin (increasing the probability that $\left.U\left(e^{*}\right)>\bar{U}\right)$.

Turning to incentives, in our formulation, financial incentives will lead to increases 
in an agent's effort $\left(\frac{d e^{*}}{d p}>0\right)$, both for matches and mismatches. ${ }^{2}$ Since, ceteris paribus, incentives increase utility, they must also increase the probability that the contract offer satisfies the participation constraint.

As with matching, incentives will lead to increases on both the intensive and extensive margins. What is notable is that our framework predicts that incentives will have a stronger effect on both the effort of mismatched agents (i.e., $\frac{d e^{*}(\theta=-1)}{d p}>$ $\left.\frac{d e^{*}(\theta=1)}{d p}\right)$ and on whether the participation constraint is satisfied (see Appendix A.1 for the details).

Lastly, we expect that the intensity of mission preferences will affect effort levels. For matches, greater intensity leads to greater effort $\frac{d e^{*}(\theta=1)}{d \gamma}>0$, while the opposite is the case for mismatches $\frac{d e^{*}(\theta=1)}{d \gamma}<0$. The intuition is simple: those who really care about a mission will work harder when matched, while those who care but are mismatched will strenuously resist working. As before, we expect the intensity of preferences to affect the extensive margin too; greater intensity will lead to an increased likelihood of working for matches and a decreased likelihood for mismatches.

To summarize, we expect both matching and incentives to increase an agent's effort level and the probability that the agent engages in work at all. While these predicted effects are mostly straightforward, our formulation also yields a few, more subtle, insights. In particular, high-powered financial incentives should have stronger effects on mismatched agents, and matching should have greater effects on agents with strong preferences.

\section{Study Design}

\subsection{Overview}

Our study was designed with three primary goals in mind. First, given the focus of the previous work in this area has been on the effect of mission matches (Fehrler and Kosfeld, 2012, Gerhards, 2012), we thought it would be useful to create a situation closer to our conceptual framework in which we could assess the impact of both

\footnotetext{
${ }^{2}$ We see our mission utility as, potentially, a component of intrinsic motivation. As a result, financial incentives could theoretically crowd out this utility and result in lower effort levels with a different setup (Benabou and Tirole, 2003). However, this is not the case in our model and, despite the mounting evidence of crowding recently reviewed by Bowles and Polania-Reyes (2012), this is not what we find in the data.
} 
matches and mismatches. Although some workers accrue benefits from being in a job with which they match well, others may suffer through a similar job because they don't believe in the organization's mission. We are interested in how much effort is enhanced or dispirited depending on the quality of the match. Second, we wanted to assess the potential impact of financial incentives on the efforts of matched and mismatched workers - the obvious question here is whether incentive pay could overcome any blunting of motivation caused by a poor match. Third, we decided to focus on the pure causal effects of mission match and financial incentives on effort, not the effects that might have to be filtered through the (potentially interesting) process of job or worker selection. Together, these three criteria lead to the random assignment of workers to a simple two-by-two design: mission match versus mismatch crossed with weak versus strong financial incentives.

We decided to use the real effort paradigm because it would generate conservative estimates of any treatment effects. Considering the tradeoffs, van Dijk et al (2001) were among the earliest to notice that treatment effects discovered in chosen effort experiments tended to be considerably smaller in real effort experiments, consistent with the idea that intrinsically motivated participants work hard, often regardless of the incentives. Their results suggest that if one uses similar chosen effort experiments as a baseline, team members shirk much less than expected and tournaments extract less additional effort compared to piece rates than one might have expected. Similarly, Gneezy and List (2006) find muted effects of reciprocity in a real effort gift exchange setting and Hennig-Schmidt et al (2010) find no effect on effort of substantial wage increases in a data entry field study.

Similarly, we thought we could improve the external validity of our results by utilizing naturally occurring preferences for a mission and by making the real effort task similar to what many workers in this sector actually do. Not only is it more natural, and perhaps less invasive, to measure the home-grown preferences for a particular mission than it is to try to create them, it might also be difficult to reliably construct mission preferences. Eckel and Grossman (2005), for example, illustrate how hard it is to prime teammates with a common mission. As for the task itself, we settled on clerical work for an organization, the type of work often associated with entry-level positions. In this way our task is more natural and representative than other related experiments in which participants earn money that they can then donate to an organization. Further, the task yields an unambiguous measure of output, which given 
the simplicity of the work, we take as a proxy for effort.

All of our design choices culminated in the following experiment, which piggybacked on the 2012 presidential election in the United States. Our study design is illustrated in Figure 1. Right after the students returned to campus in early September, we sent out a web survey to record their political preferences and the intensity of those preferences. We used the preference data to type our potential participants. Approximately two weeks later (so as to minimize any links between the survey and our experiment) we began bringing students to the lab to do a letter-stuffing experiment. In a first round, all participants stuffed fundraising letters into envelopes for the College to assess their ability. In a second round, participants were randomly assigned to stuff campaign letters for one of the two major party candidates (Obama or Romney). Because the student preferences skewed Democratic at the College, to assure balance, prior to their arrival in the lab, we used a unique but anonymous identifier (postal box numbers on campus) to stratify our participants and assure equal numbers of matches and mismatches for the two preference groups. Overlaying the matching, we also randomly assigned financial incentives. After working for a candidate in one of the four cells of our design, the experiment ended for the participants with another brief survey and payments. We now expand on each aspect of the experiment.

\subsection{Agent Mission Preferences}

In our study, the political preferences of respondents represent the agent's mission preferences. To measure political preferences, a baseline survey was conducted where respondents were asked for their voter registration status (if registered and party affiliation), which major party candidate (Obama versus Romney) they would vote for, and whether they had a preference for who would win the election. In addition, using the same question that is on the American National Election Studies survey (ANES, 2012), we asked respondents where they would place themselves on the following 7-point likert scale: ${ }^{3}$

\footnotetext{
${ }^{3}$ In Appendix A.2, we present the distribution of political preferences for the entire sample of survey respondents.
} 


\begin{tabular}{|c||c||c||c||c||c|c|}
\hline $\begin{array}{c}\text { Strong } \\
\text { Democrat }\end{array}$ & Democrat & $\begin{array}{c}\text { Lean } \\
\text { Democrat }\end{array}$ & Independent & $\begin{array}{c}\text { Lean } \\
\text { Republican }\end{array}$ & Republican & $\begin{array}{c}\text { Strong } \\
\text { Republican }\end{array}$ \\
\hline \hline$(1)$ & $(2)$ & $(3)$ & $(4)$ & $(5)$ & $(6)$ & $(7)$ \\
\hline
\end{tabular}

Based on the response to this question, we classified participants as Democrats if they describe themselves as a strong Democrat, Democrat, or someone who leans Democrat, and we classified participants as Republicans if they describe themselves as Leaning Republican, Republican, or a strong Republican. To test whether these classifications represent actual policy choices, we examine the correlation between being classified as a Democrat and agreement with a range of policy statements developed by Pew Research (PEW, 2012). We find that our party classification is strongly correlated with the role that government should take on issues such as taxation, environmental regulation, social safety nets, immigration, health care, abortion, and labor unions (see Appendix Table A.7).

As suggested in Section 2, we hypothesize that in addition to having clear campaign preferences, participants will vary in the intensity of these preferences. For example, although two individuals might both report being Democrats, one might be more passionate about the party's mission than the other. To measure the intensity of our respondent's political preferences, we ran a version of the dictator game similar to Carpenter and Myers (2010). Respondents were given an endowment of $\$ 100$ that they could split with the campaign of a major party candidate. They were told that once the survey was finished we would randomly pick five people and enact their choices. Respondents first picked between "Obama," "Romney" and "I do not want to allocate any money and will keep the $\$ 100$ for myself". Conditional on picking either candidate, they then inputted the amount that should be sent to the candidate's campaign and, implicitly, the amount they wished to keep. It was understood that the amounts kept would be sent anonymously to the campus mailboxes of the randomly selected respondents. We use the amounts sent to either candidate as a measure of the intensity of mission preferences. ${ }^{4}$

\subsection{Principal Missions}

In previous studies, the organization or principal had a mission that resulted in the direct provision of a collective good. In our study, the organization (political party)

\footnotetext{
${ }^{4}$ The results of the political dictator game are summarized in Appendix A.2.
} 
will campaign to elect public officials that will be charged with not only providing collective goods, but deciding whether they should be provided in the first place. For instance, Democrats support the provision of health insurance by the government, while the Republicans believe that the government should have a minimal role in providing health insurance coverage (Grassley, 2009). There are other stark differences between the two parties, which broadly generalize on the level of taxation and expenditures. Several studies have demonstrated relationships between party control of government and taxes, health care spending, family assistance, worker's compensation, and overall expenditures (Besley and Case, 2003, Reed, 2006, Grogan, 1994).

For mission alignment to matter, not only must there be actual differences between the two political parties, agents must perceive these differences. In our sample, 99\% answered yes when asked "Are there important differences in what Republicans and Democrats stand for?" In addition, a vast majority of our respondents answered the following party-specific questions correctly: "Which candidate supports restricting access to abortion?", "Which candidate supports raising taxes on incomes over $\$ 250,000$ ?", "Which candidate supports allowing many illegal immigrants who were brought to the U.S. as children to remain in the country?" and "Which candidate opposes allowing gays and lesbians to marry legally?"

Finally, we worried that participants would not only vary in their political preferences but that they would also vary in where they believed each candidate should be placed on the spectrum. We asked respondents (using the method of Krupka and Weber, forthcoming) where they thought the "average American" would place both candidates on the same 7-point scale. Fortunately, our worries were misplaced - there was near unanimity on the placement of the two candidates: 95\% labeled Obama a "Democrat" or a "strong Democrat" and $94 \%$ labeled Romney as a "Republican" or a "strong Republican". Further, one's own political orientation did not predict how one labeled the two candidates.

\subsection{Matching, Incentives and Balance}

We ran twelve experimental sessions with 207 participants. We exogenously varied mission alignment between agents and principals by randomly assigning study participants to work for either the Obama or Romney campaigns. Individuals classified as a Democrat (Republican) and are randomly matched with the Obama (Romney) cam- 
paign are considered mission matched, while those assigned to the opposite campaign are mismatched.

Each session was randomized into one of three financial incentive treatments: A base pay of $\$ 20$ for 15 minutes of production, the base pay plus a piece rate of $\$ 0.50$ per completed letter or the base plus $\$ 1.00$ per completed letter. Because behavior did not differ between the two strong incentive treatments we collapsed them to simplify the analysis and compare low-powered incentives (i.e., the base wage only) to highpowered incentives (i.e., base plus any piece rate); however, in the appendix (Table A.12) we show that disaggregating the data by the three incentive treatments does not affect our results.

In Table 1 we compare baseline characteristics between those who are matched and mismatched (Columns 1-3), and compare those receiving the base pay to those receiving the base pay plus incentives (Column 4-6). To measure intrinsic motivation, we ask how much effort on a scale from 0 to 10 a respondent would exert for a minimum wage job. Reassuringly, this measure appears balanced across the cells.

One concern that might arise from the experiment is that the workers who were randomly matched or selected to receive high-powered incentives also, by bad luck, have greater natural ability to address and stuff envelopes. To account for this, we ran the first "ability" round where participants addressed and stuffed fundraising letters for the College. ${ }^{5}$ We can see in Table 1 that the number of letters completed between participants in the mismatch and matched arms are relatively similar. There is a slight difference however between the low-incentive and high-incentive arms which is statistically significant at the $5 \%$ level. The first thing to note, however, is that it appears that participants in the high-incentive arm have slightly lower ability, which goes against us finding any effects of incentives on productivity. Secondly, when we control for ability, the effects of matching and high-powered incentives are virtually unchanged. Finally, when we examine the change in output between the ability round and production round, we find that both matching and incentives have strong and significant effects on changes in output.

Overall, our sample across the various treatment arms appears balanced on observables. Comparing the match and mismatch arms, we find no differences that are statistically significant (out of 15 comparisons) and one significant difference between the base and incentive arms. As seen in the next section, controlling for ability in the

\footnotetext{
${ }^{5}$ All participants agreed with the College's mission statement.
} 
analysis does not change our results.

\subsection{Session Protocol}

At the beginning of each session, participants signed in using their postal box number and received a packet containing instructions, letters, envelopes and address lists, divided into two sealed bundles (the experimental instructions can be found in Appendix A.3). Each session was divided into two parts. In the first part of the experiment, and without any knowledge of what would come next, participants were asked to address and stuff letters for the College without compensation. The address list, letters, and envelopes were contained in this first bundle. The letters were thank you notes to donors. Participants were told to see how many they could correctly complete in 15 minutes. Again, we use the number of complete letters in this part as a baseline measure of ability.

The second part of the experiment was the production task from which we take our output measures. The instructions informed participants that they would have 15 minutes to address and stuff campaign letters for one of the two major party candidates. The letters simply stated, in broad terms, the official platform of each campaign and were taken from the campaign websites. The address list used consisted of independent voters in Hamilton County Ohio, a contested county in an important swing state. This list along with the campaign letters and envelopes were contained in the second bundle.

At the completion of the production phase of the experiment, participants collected their work while we handed out a survey. The brief follow-up survey asked a number of the same political preference questions as our baseline survey to look for mission preference stability. Indeed, preferences were stable - treating the scale cardinally, the correlation between pre- and post-experiment political preferences is high $(\rho=0.9, p<0.01)$. The session ended with participants being paid, one at a time. The average earnings were $\$ 25.74$ for sessions that took about an hour. 


\section{Empirical Analysis}

\subsection{Overview of Data}

Our analysis focuses on our effort proxy - the number of campaign letters produced in the 15 minute production phase where workers are randomly matched to a political campaign and a pay scheme. Before formally estimating the effects of matching and incentives, we present a summary of the main average treatment effects (along with 95\% confidence intervals) in Figure 2. The left panel confirms a large and statistically significant difference in output between matched and mismatched workers; matched workers produce an average of 15.63 letters compared to 9.07 letters for mismatched workers or an increase of $72 \%$ due to matching. We also find that, overall, workers respond well to incentives; in the right panel we see that average output increases by $35 \%$ (from 10.49 letters with base wages to 14.18 with incentives).

Given our theoretical predictions we examine both whether or not a participant produced any campaign letters (i.e., the extensive margin) and, conditional on producing something, how much was produced (the intensive margin). In Figure 3, we present the distributions of output by treatment. The first thing to notice is that matching has a strong effect on the extensive margin. Between $25 \%$ and $45 \%$ of participants produce nothing when they are mismatched while there is just one instance of producing nothing among the matches. The incentives also appear to matter, especially for the mismatches. Here the incidence of producing nothing falls almost in half and there are many more observations of output in the middle of the observed range. For the matches, mean output appears to increase slightly when incentives are used but the big effect seems to be a reduction in the variance of output.

\subsection{Estimating Equation}

We estimate the following model using OLS:

$$
\begin{aligned}
\text { Output }_{i}= & \alpha+\beta_{1} \text { Match }_{i}+\beta_{2} \text { Incentive }_{i} \\
& +\beta_{3} \text { Match }_{i} \times \text { Incentive }_{i}+X_{i}^{\prime} \lambda+\varepsilon_{i}
\end{aligned}
$$

where Output $t_{i}$ is the number of campaign letters completed during the session (or, 
when we examine the extensive margin, Output $t_{i}$ is an indicator for whether any

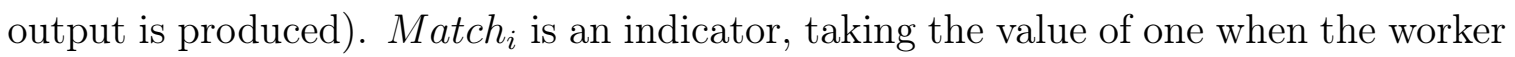
is mission matched and Incentive $_{i}$ is another indicator taking the value one when the worker is assigned incentives (i.e., the base pay plus a piece rate). The interaction term Match $_{i} \times$ Incentive $_{i}$ picks up any differential effects of incentives on those that are matched. The vector $X^{\prime}$ includes ability (the number of College letters completed in the first part of the session), political preferences, gender, ethnicity, effort an individual would exert if working for minimum wage, whether an individual was born in the US, and whether the individual is a registered voter.

\subsection{Effects of Matching}

Table 2 presents estimates for the effects of mission match on output. In Column 1, we find similar results to what we saw in Figure 2, matching leads to an increase of $72 \%$ in output compared to mismatches. These effects are similar when we control for ability and the set of individual characteristics (Column 2). There could be two reasons for these large effects; matches are more willing to work for their campaigns (since they believe in the mission) or that they simply work harder when matched. We therefore examine the effects of matching on both the extensive and intensive margin to disaggregate the result. We find that matching increases the probability of working by 33 percentage points, which is a $56 \%$ increase compared to participation rates of 66 percent in the mismatched group (columns 3-4). Matching leads to changes on the intensive margin as well. Conditional on working (column 6), matching is associated with a $19 \%$ increase in output. Overall, matching appears to strongly affect both the decision to work and the level of effort exerted.

To examine the robustness of our results, we use alternative means of classifying respondents as Democrats or Republicans. For example, we classify respondents by which candidate they prefer to vote for and to which political party they are registered. We find very similar results under these alternative classifications (see Appendix Table A.8). We also cluster our standard errors on the session level and find little change in the precision of our estimates (Appendix Table A.9). Finally, we examine the change in output between the production and ability rounds and find that matching leads to large and significant increases in output between the two (Appendix Table A.10).

The effects presented here are consistent with the theoretical model from section 
2. Agents exert more effort when the mission preferences of workers align with those of the principals.

\subsection{Effects of Incentives}

We now turn to estimating the effects of incentives on output (Table 3). Not surprisingly, workers respond strongly to incentives. Examining the overall effects of incentives in Column 1, we find that incentives lead to a $35 \%$ increase in output. We find that incentives increase the likelihood of working (Column 3) by $8 \%$ and increase effort (column 5) by $23 \%$. Comparing the magnitudes of the effects, we find that matching generates larger productivity gains than incentives (Column 1). This suggests that organizations that can screen and identify agents that have similar preferences for the mission maybe able to economize on high-powered incentives.

Our conceptual framework predicted that incentives should have stronger effects for mismatched workers (compared to matched workers). Comparing means, mismatched workers without incentives produce 6.33 envelopes while those with incentives produce 11.75 , a $86 \%$ increase. By comparison, the difference shrinks to (16.5714.65) 1.92 envelopes, an increase of $13 \%$, for matched workers. In the context of Table 3, we confirm that incentives have a much larger effect on mismatches $(+6.17$ letters) than on matches $($ Incentive + Match $\times$ Incentive $=+2.01)$ and that this difference is significant at the $1 \%$ level.

It also appears that incentives dramatically increase the probability of working for mismatches $(+15 \%)$, however, the effect is marginally significant $(\mathrm{p}=0.107)$. By comparison, incentives have very little influence on the extensive margin for matched workers; this is not surprisingly since $98 \%$ of matched workers with a base compensation decide to work. Conditional on working (Column 6), incentives again have stronger effects on mismatched workers $(+6.14)$ compared to matched workers $(+1.93)$, and this difference is also significant at the $1 \%$ level.

As we did in the previous section, we also look at the effects of incentives on the change in output between the ability and production rounds. We find large and significant effects of incentives on the changes in output (Appendix Table A.11).

As noted in section 3, our study design varied the incentive payments so that participants were randomly offered either $\$ 0.50$ or $\$ 1.00$ per letter. When we examine the effects of incentives with these two piece rates disaggregated, we find similar 
results. Both piece-rates have positive and significant effects on output, and they both also have stronger effects on mismatches than on matches (see Appendix Table A.12). ${ }^{6}$

The differential effects of incentives that we find suggest two considerations when designing compensation schemes. First, incentives appear to have very muted effects when workers are able to match correctly on mission. Second, when workers are mismatched, incentives can imperfectly substitute for mission preferences; in other words incentives are able to make up a large portion of the loss in output due to mismatching. For example in Column 2, we find that while matching leads to an increase of 9 letters, providing incentives captures $68 \%$ of this effect (increasing output by 6.2 letters).

To summarize, we find that both matching and incentives have strong effects on worker's output, effects that reverberate along both the extensive and intensive margins. As predicted, we also find that incentives have differential effects on output depending on the quality of the match.

\subsection{Intensity of Preferences}

Our conceptual framework suggests that the intensity of preferences should also affect effort. Workers with stronger preferences for a mission should work harder when matched compared to those with weaker preferences. Conversely, workers with stronger preferences should exert less effort when mismatched compared to those with weaker preferences. In other words, matches and mismatches should matter much more for workers who actually care about the mission. As previously described in section 3, we measure the intensity of preferences using a dictator game; the idea being that larger monetary contributions to a candidate indicator stronger preferences for the candidate's mission. To examine the effects of intensity, we regress our output measures on either the actual amount contributed or an indicator for any amount contributed separately for matches and mismatches (Table 4).

Panel A presents results for those workers who were matched. We find that preference intensity has little effect on matched agent output (Column 1), and this holds for both the extensive and intensive margins (Columns $3 \& 5$ ), as well as when

\footnotetext{
${ }^{6}$ The differences between the $\$ 0.50$ and $\$ 1.00$ piece rate are not statistically significant in any specification.
} 
we use an indicator to capture any positive contribution to a candidate (Columns 2,4 $\& 6)$.

For mismatched workers (Panel B), the intensity of preferences does seem to matter. We find that greater intensity leads to lower output when workers are mismatched (Columns $1 \& 2$ ). For each $\$ 10$ increase in the amount given to the preferred candidate, mismatched workers produce 0.47 fewer letters, or approximately $5 \%$ fewer letters (mean output for mismatched workers is 9.1 letters). Workers who gave any amount reduce output by $31 \%$ when mismatched. These decreases in output are seen on both the extensive and intensive margins, although many of these estimates are imprecise (Columns 3-6).

Finally, to compliment this analysis, we examine the effect of political distance on output, or how close (far) is a worker's political preferences are to the candidate to which she was randomly matched. Recall that all study participants were asked to place themselves on a 7-point Likert scale (see section 3.2). In addition, participants were asked to place both Obama and Romney on the same scale. By taking the difference (in absolute value) between the worker's political preferences from how they ranked the candidate they were randomly assigned to work for, we generate a political distance measure. For example, a worker who ranked herself as a "Democrat", Obama as a "Democrat", and Romney as a "Republican" would have a political distance of zero if assigned to work for Obama and a distance of four if assigned to work for Romney. We estimate the following model:

$$
\begin{aligned}
\text { Output }_{i}= & \alpha+\gamma_{1} \text { Distance }_{i}+\gamma_{2} \text { Incentive }_{i} \\
& +\gamma_{3}\left(\text { Distance }_{i} \times \text { Incentive }_{i}\right)+X_{i}^{\prime} \lambda+\varepsilon_{i}
\end{aligned}
$$

where we expect $\gamma_{1} \leq 0$, or that political distance reduces a worker's effort resulting in less output. The vector $X^{\prime}$ includes the same set of controls from equation 2. In the event that there are non-linearities in our political distance measure, we also estimate equation 3 using indicators for each political distance (ranging from 0 to 5$).^{7}$

We find, consistent with our previous analysis, that political distance matters

\footnotetext{
${ }^{7}$ Given the very few workers who have a political distance of six, we group these workers in with those who have a political distance of five.
} 
(Table 5). A one unit increase in political distance results in 2.25 fewer letters produced (Column 1), and this effect is seen on both the extensive and intensive margin (Columns $2 \& 3$ ). We also find that incentives mitigate the effect of political distance (Distance $\times$ Incentive). Using indicators for each distance, we observe that the relationship is monotonic (Column 4). For example, we see that being one unit away results in no significant change in output, but being 4 units away results in 6.88 fewer letters (and we can reject the null that these effects are the same with a p-value < $.01)$. This pattern of greater distance resulting in less effort is also seen on both the extensive and intensive margin (Columns $5 \& 6$ ).

\section{Discussion}

\subsection{Matching Upper Bounds}

To this point, we consider our results estimates of an upper bound on the effects of mission matching on productivity since, so far, we compare matches to mismatches, not to workers without mission preferences, i.e., "no-matches". This combined effect is not small - matching increases productivity by $72 \%$ compared to agents who are mismatched and, consistent with our results being upper bounds, previous studies find smaller effects. Tonin and Vlassopoulos $(2010,2012)$ find in two separate experiments involving data entry, that when workers are matched with an organization that contributes to a charity of their choice they observe increases in productivity of between 10 to $20 \%{ }^{8}$ In two studies based on chosen effort estimates, Fehrler and Kosfeld 2012 find an increase of 27\%, while Gerhards (2012) finds an increase of 32\% - in both cases agents can choose a charity or humanitarian project to which contributions will be made. On the extensive margin, Gregg et. al. (2011) using observational data, finds that workers in the non-profit sector are $12 \%$ more likely to agree to unpaid overtime, an effect well within our estimate of a $33 \%$ increase in the probability of working when agents go from being mismatched to matched.

Taken together, the previous studies suggest positive but modest gains to matching which, considering our substantial upper bound estimates of the total possible effect,

\footnotetext{
${ }^{8}$ Specifically, Tonin and Vlassopoulos (2010) find that women (and not men) increase their productivity by $10 \%$ when they can choose the charity a donation will be made to, while in their 2012 paper, they find a $20 \%$ increase in productivity regardless of whether the donation to the charity was a lump-sum or a function of the worker's effort.
} 
suggests that the disincentive effect of a mismatch must be considerable. We attempt to disentangle the effects of the two forces in the following section.

\subsection{Separate Effects of Matching and Mismatching}

To separately identify the effects of matching and mismatching on productivity, we would ideally generate a group that had no preferences for mission and observe their output. We could then make comparisons to the output of matched and mismatched workers giving us estimates on the individual effects of matching and mismatching. However, it is difficult to find workers who are completely indifferent to the mission at hand; in our context these would be workers that have absolutely no political preferences. Though not too surprising, it appears that almost all young college students have political preferences. In our baseline survey, we found over $90 \%$ had a preference for one presidential candidate over the other. That said, not everyone appeared to have intense preferences. Returning to our model, if preference intensity $(\gamma)$ is set to zero the intrinsic motivation term $\theta M(e, \gamma)$ disappears (i.e., $\gamma \rightarrow 0 \Rightarrow M(e, \gamma) \rightarrow 0$ ) and we have the standard, extrinsically motivated, agents from personnel economics, precisely the workers we need (Comparative statics involving the no-match group can be found in Appendix A.1).

We thus exploit our preference intensity data from the dictator game to classify participants who contributed nothing to either candidate in the dictator game. We call these workers "no-matches" and propose that these types have either no or very weak preferences for missions. ${ }^{9}$ Types that contribute positive amounts in the dictator game continue to be either matched or mismatched. Splitting our workers into three groups allows us to examine the production of mismatches, no-matches, and matches. Before turning to the analysis, we note that we are more cautious when interpreting these results because assignment to the no-match group is not randomly determined. ${ }^{10}$ That said, it is difficult to envision how a worker's preferences for missions could be experimentally varied (without deception) in this setting.

\footnotetext{
${ }^{9}$ Corroborating this assumption, we find that amounts given in the dictator game are strongly correlated with "feeling thermometers" commonly used by political scientists to gauge a voter's preference for a specific candidate.

${ }^{10}$ For example, one might hypothesize that those giving nothing in the dictator game might also have less income. However, using the median household income for each zip code, we find no statistically signficant correlation between the amount given in the dictator game and median household income for zip code of a particpant's residence.
} 
Figure 4 presents the average treatment effects when we parse out the no-match group. We find, as expected, average output increases when moving from mismatches (7.3 letters) to no-matches (12.8 letters) to the matched group (15.8 letters). To add more precision to our analysis, we estimate the following model:

$$
\begin{aligned}
\text { Output }_{i}= & \alpha+\delta_{1} \text { Match }_{i}+\delta_{2} \text { Mismatch }_{i}+\delta_{3} \text { Incentive }_{i} \\
& \delta_{4}\left(\text { Match }_{i} \times \text { Incentive }_{i}\right)+\delta_{5}\left(\text { Mismatch }_{i} \times \text { Incentive }_{i}\right)+X_{i}^{\prime} \lambda+\varepsilon_{i}
\end{aligned}
$$

where the excluded category is the no-matches. In this equation, $\delta_{1}$ and $\delta_{2}$ are the separate effects of matching and mismatching when compared to the no-match group. Since we expect incentives to have differential effects depending on if a worker is matched or not, we include interaction terms between matching (mismatching) and incentives. The vector $X^{\prime}$ includes the same set of controls from equation 2 .

Estimates of (4) are presented in Table 6. Both matching and mismatching lead to large changes in output (Columns 1 \& 2). Based on estimates from Column 1 , matching leads to a $27 \%$ increase in output where mismatching leads to a $43 \%$ decrease in output. Similar to our previous results on matching, workers are responding on both the extensive and intensive margin when matched and mismatched (Columns 3-6).

Turning to incentives, Figure 5 shows that they have their strongest effects on the mismatch and no-match group. For mismatches, it appears that incentives are sufficient to raise output to the same level as no-matches (with base compensation). In addition, incentives are effective at raising output for no-matches to similar levels as the matched group of workers (with base compensation). Both suggest that incentives are close substitutes for mission matching. As further evidence, our estimates in Table 6 (Column 2) show that matching leads to an increase of 4.92 letters, while incentives lead to an almost identical increase of 4.81 letters. For mismatched workers, there is a similar result. Mismatching leads to a reduction of about 6 letters, but providing mismatches with incentives increases production by about 6 letters (Incentive + Mismatch $\times$ Incentive); in other words, incentives mitigate any loss in productivity due to a poor match.

An alternative method of creating a no-match group is to look at party affiliation. In our sample, $43 \%$ are registered members of the Democratic Party and 10\% 
are registered members of the Republican Party. Classifying matches as registered Democrats (Republicans) matched with Obama (Romney), and mismatches otherwise. We can create a no-match group using all other party affiliations (Libertarian, Independent, and No affiliation). We estimate equation 4 using this alternative classification system, and find strikingly similar results to those just discussed (Appendix Table A.13).

\section{Concluding Remarks}

Our results dovetail nicely with the Gallup survey mentioned at the outset. In this large survey, agents who seemed well-aligned with the mission of the organization at which they worked were more engaged and productive. Our matched agents work hard too, and consistent with theory, they seem intrinsically motivated to do so. Also consistent with the Gallup results, our mismatched (and "no match") agents are both less productive and relatively more responsive to financial incentives. What differentiates our work, however, is that our experimental design allows us to estimate the magnitude of these effects precisely without having to worry about the confounding effects of selection.

Because the effects that our experiment reveals are large, our study has implications for human resource policies at any organization. For those organizations without a clear mission statement, our results confirm empirically, what the management literature has suggested for decades - write one and use it, if possible, to attract (and screen for) intrinsically motivated workers. Not only are your workers likely to be content and productive, potentially costly, high-powered incentives are probably not necessary. If screening on the mission is not possible (or not credible) for the organization, our results suggest that high-powered incentives can overcome much of the motivational deficit caused by poor matches and a more general lack of intrinsic motivation.

Our estimates suggest that the returns to screening and sorting are large and, at least partially, stem from the substitutability of "mission utility" for extrinsic incentives. Realizing this is great for non-profit organizations on a shoestring budget; but the same fact may allow other, better-funded, organizations to take advantage of worker goodwill. In other words, our results are clearly good news for principals because they imply there are two ways to motivate agents and one is much cheaper 
but welfare gains for agents are less obvious. As a recent New York Times article reports, $70 \%$ of Apple employees in the U.S. work in the company's retail outlets for about $\$ 25,000$ a year. While the skills of many of these employees should allow them to command much higher wages, they tend to stay on because, as one former employee put it, "when you're working for Apple you feel like you're working for this greater good" (Business section, June, 23, 2012). 


\section{References}

George A Akerlof and Rachel E Kranton. Identity and the economics of organizations. The Journal of Economic Perspectives, 19(1):9-32, 2005.

ANES. American national election studies. 2012.

Roland Benabou and Jean Tirole. Intrinsic and extrinsic motivation. The Review of Economic Studies, 70(3):489-520, 2003.

Timothy Besley and Anne Case. Political institutions and policy choices: evidence from the united states. Journal of Economic Literature, 41(1):7-73, 2003.

Timothy Besley and Maitreesh Ghatak. Competition and incentives with motivated agents. American Economic Review, pages 616-636, 2005.

Samuel Bowles and Sandra Polania-Reyes. Economic incentives and social preferences: substitutes or complements? Journal of Economic Literature, 50(2):368-425, 2012.

Alexander L Brown, Jonathan Meer, and J Forrest Williams. Why do people volunteer? an experimental analysis of preferences for time donations. 2013.

Jeffrey Carpenter and Caitlin Knowles Myers. Why volunteer? evidence on the role of altruism, image, and incentives. Journal of Public Economics, 94(11):911-920, 2010 .

Robert Dur and Robin Zoutenbier. Working for a good cause. 2012.

Catherine C Eckel and Philip J Grossman. Managing diversity by creating team identity. Journal of Economic Behavior \& Organization, 58(3):371-392, 2005.

Susan Ellingwood. What makes work meaningful? if you think money or prestige, think again. Gallup Business Journal, December 2001.

Sebastian Fehrler and Michael Kosfeld. Pro-social missions and worker motivation: An experimental study. Available at SSRN 2031818, 2012.

Patrick Francois. 'public service motivation'as an argument for government provision. Journal of Public Economics, 78(3):275-299, 2000. 
Leonie Gerhards. How (not) to incentivize motivated agents-an experiment with employees from a non-profit organization. Technical report, Mimeo, Goethe University Frankfurt, 2012.

Uri Gneezy and John A List. Putting behavioral economics to work: Testing for gift exchange in labor markets using field experiments. Econometrica, 74(5):1365-1384, 2006.

Chuck Grassley. Health care reform - a republican view. New England Journal of Medicine, 361(25):2397-2399, 2009.

Paul Gregg, Paul A Grout, Anita Ratcliffe, Sarah Smith, and Frank Windmeijer. How important is pro-social behaviour in the delivery of public services? Journal of public economics, 95(7):758-766, 2011.

Colleen M Grogan. Political-economic factors influencing state medicaid policy. Political Research Quarterly, 47(3):589-622, 1994.

James Harter, Frank Schmidt, Emily Killham, and James Asplund. Q12 metaanalysis. Gallup Organization, 2006.

Heike Hennig-Schmidt, Abdolkarim Sadrieh, and Bettina Rockenbach. In search of workers' real effort reciprocity - a field and a laboratory experiment. Journal of the European Economic Association, 8(4):817-837, 2010.

Erin Krupka and Roberto Weber. Identifying social norms using coordination games: Why does dictator game sharing vary? forthcoming.

PEW. The political typology, 2012. URL http://www. people-press .org/2011/05/04/about-the-political-typology/.

W Robert Reed. Democrats, republicans, and taxes: Evidence that political parties matter. Journal of Public Economics, 90(4):725-750, 2006.

Mirco Tonin and Michael Vlassopoulos. Disentangling the sources of pro-socially motivated effort: A field experiment. Journal of Public Economics, 94(11):10861092, 2010.

Mirco Tonin and Michael Vlassopoulos. Social incentives matter: Evidence from an online real effort experiment. 2012. 
Frans Van Dijk, Joep Sonnemans, and Frans Van Winden. Incentive systems in a real effort experiment. European Economic Review, 45(2):187-214, 2001. 


\section{$7 \quad$ Figures and Tables}

Figure 1: The Study Design

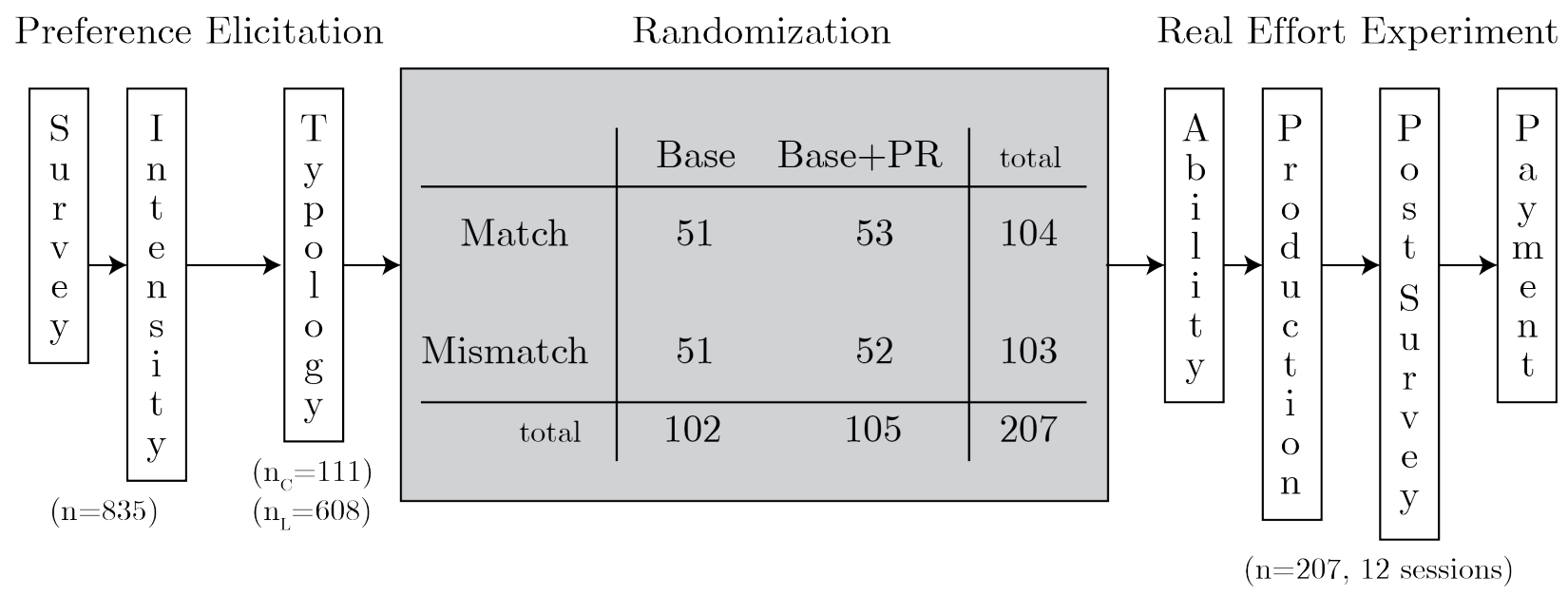


Figure 2: Effect of Mission Matching and Incentives on Worker Output
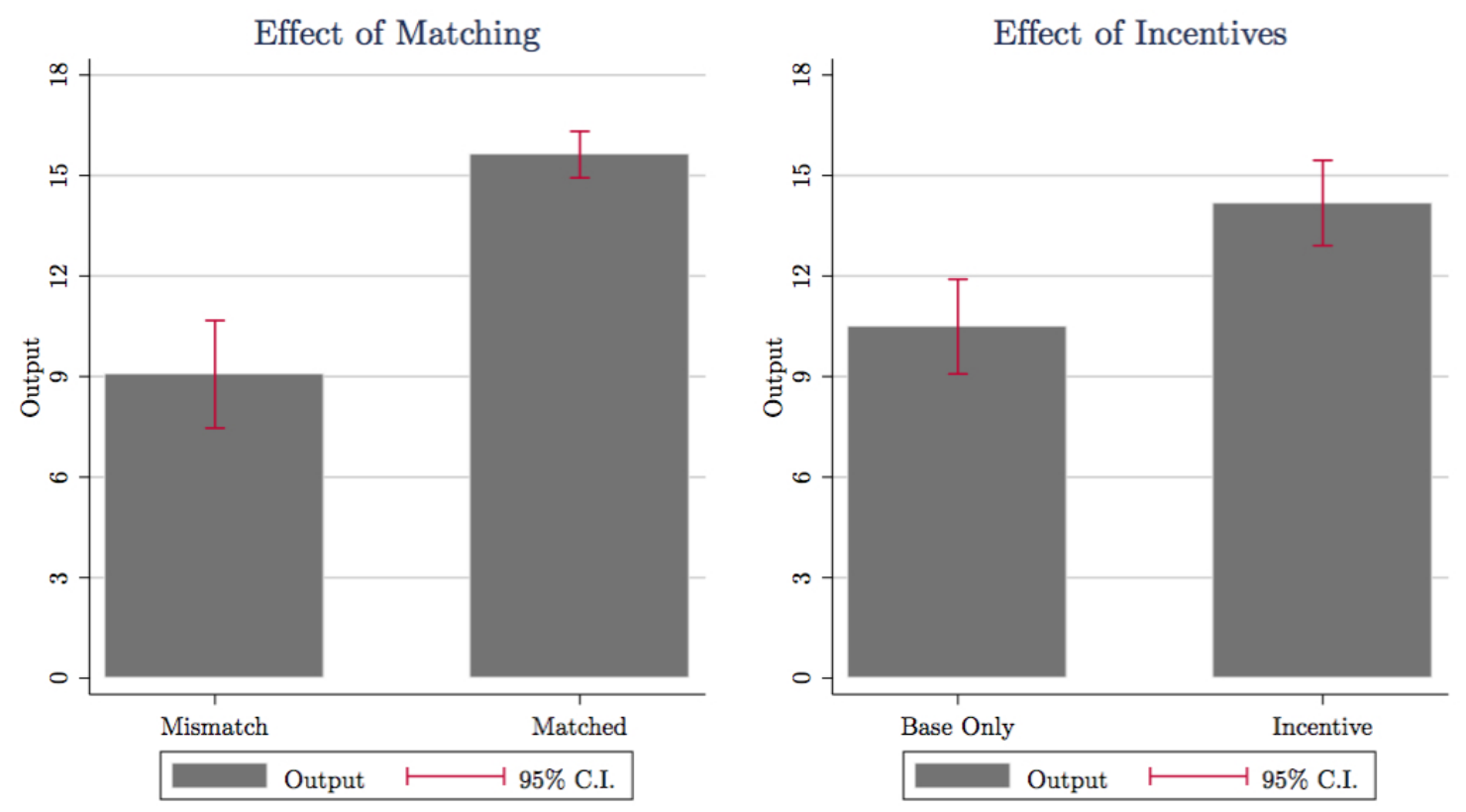
Figure 3: The Distribution of Output by Treatment
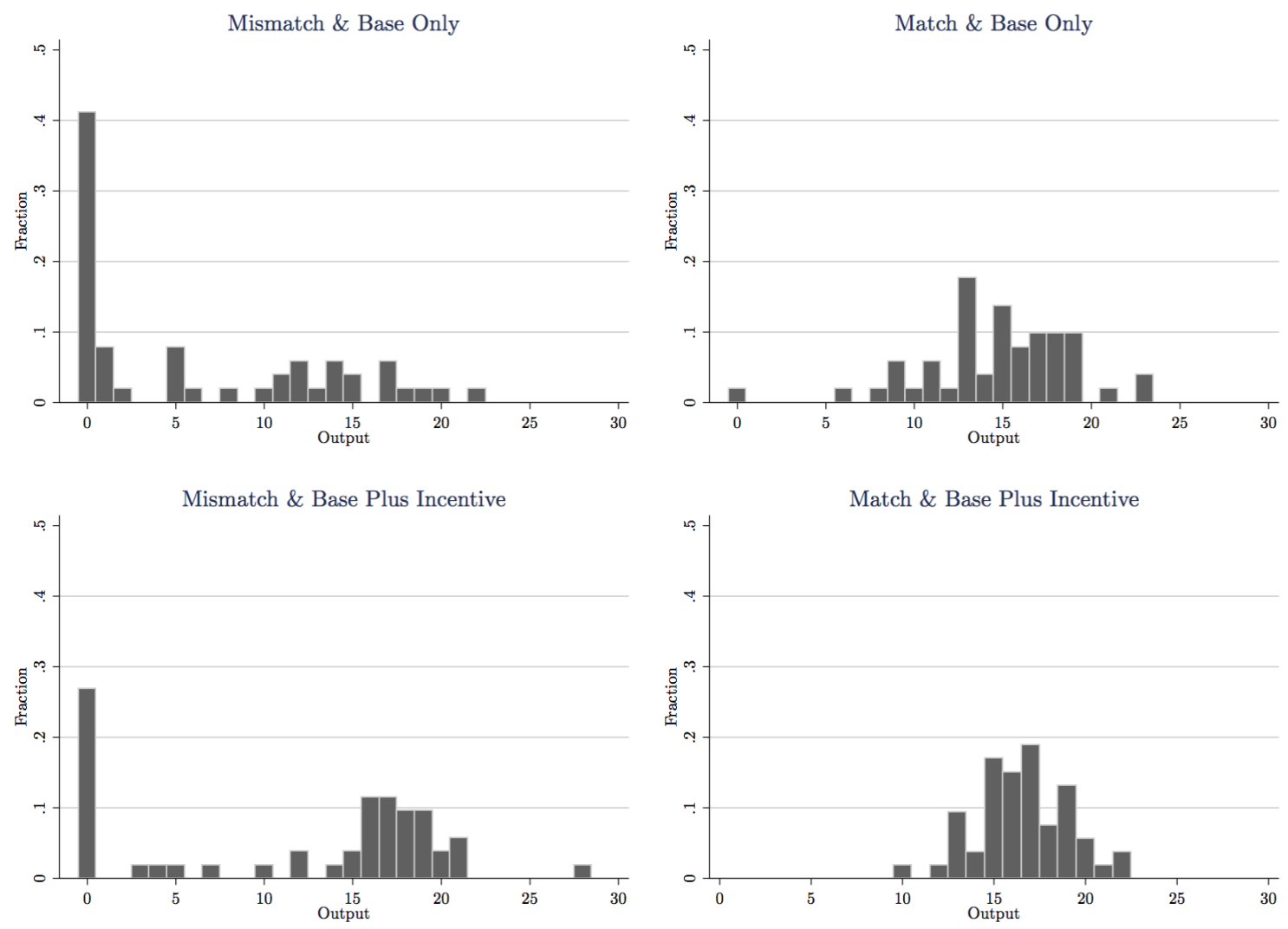
Figure 4: Effect of Mission Match on Worker Output

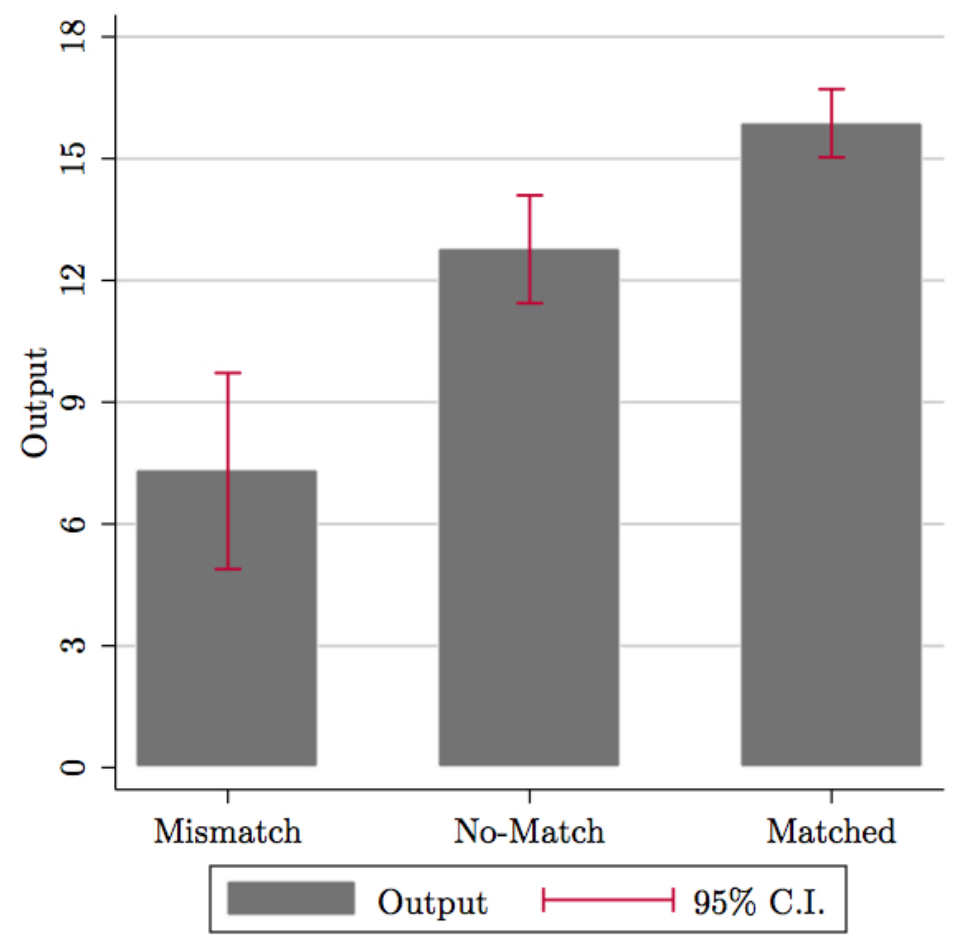


Figure 5: Effect of Incentives on Worker Output

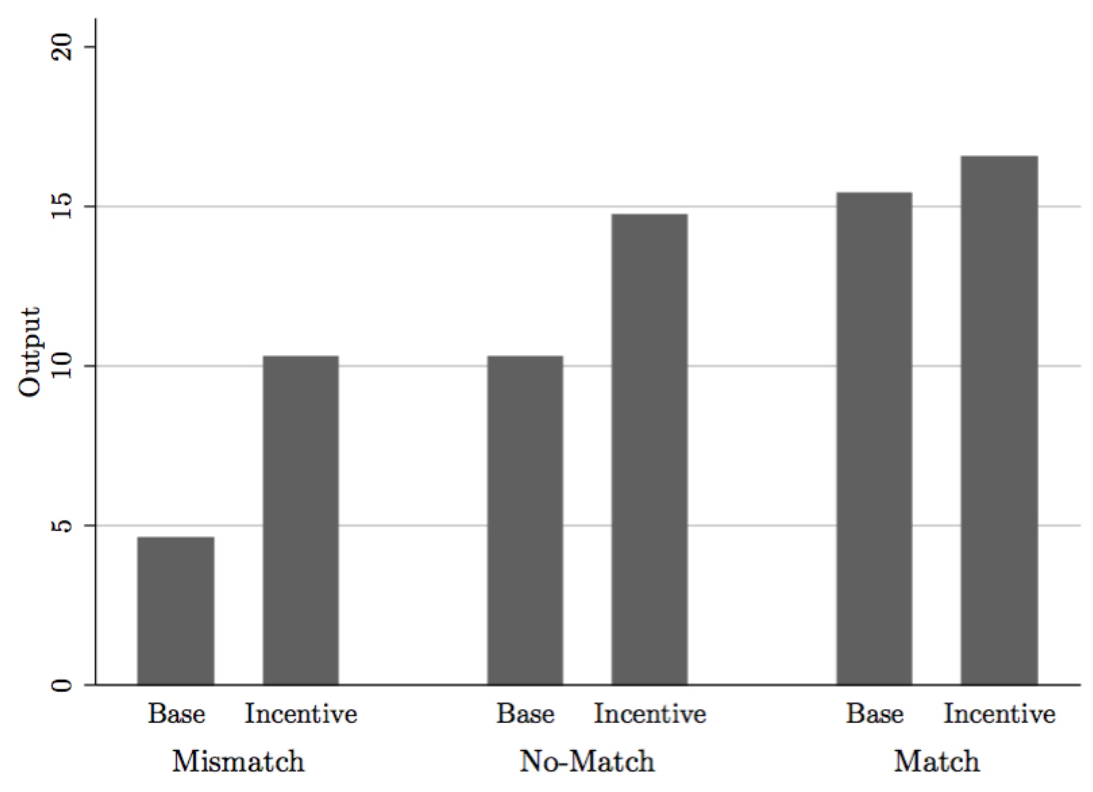




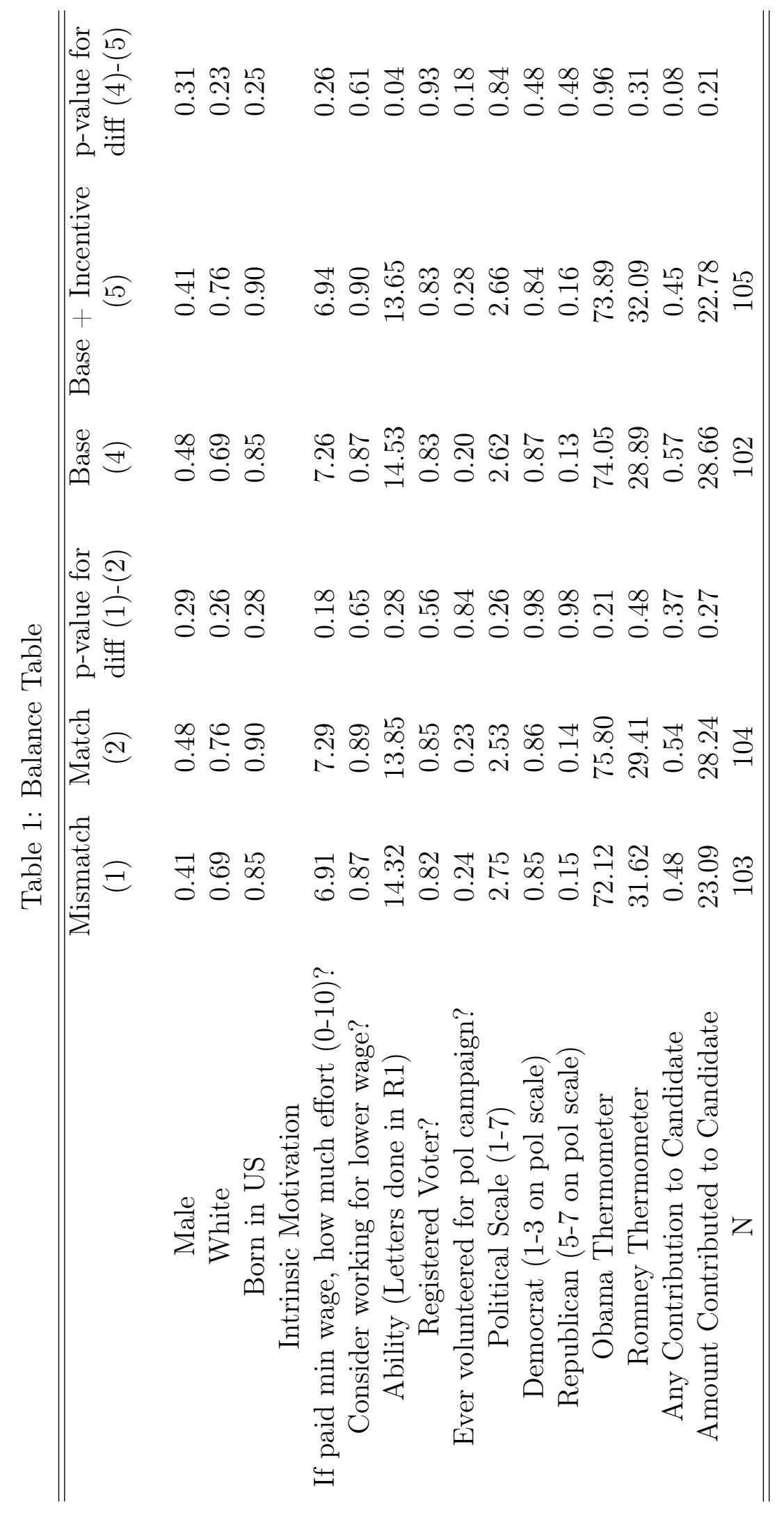




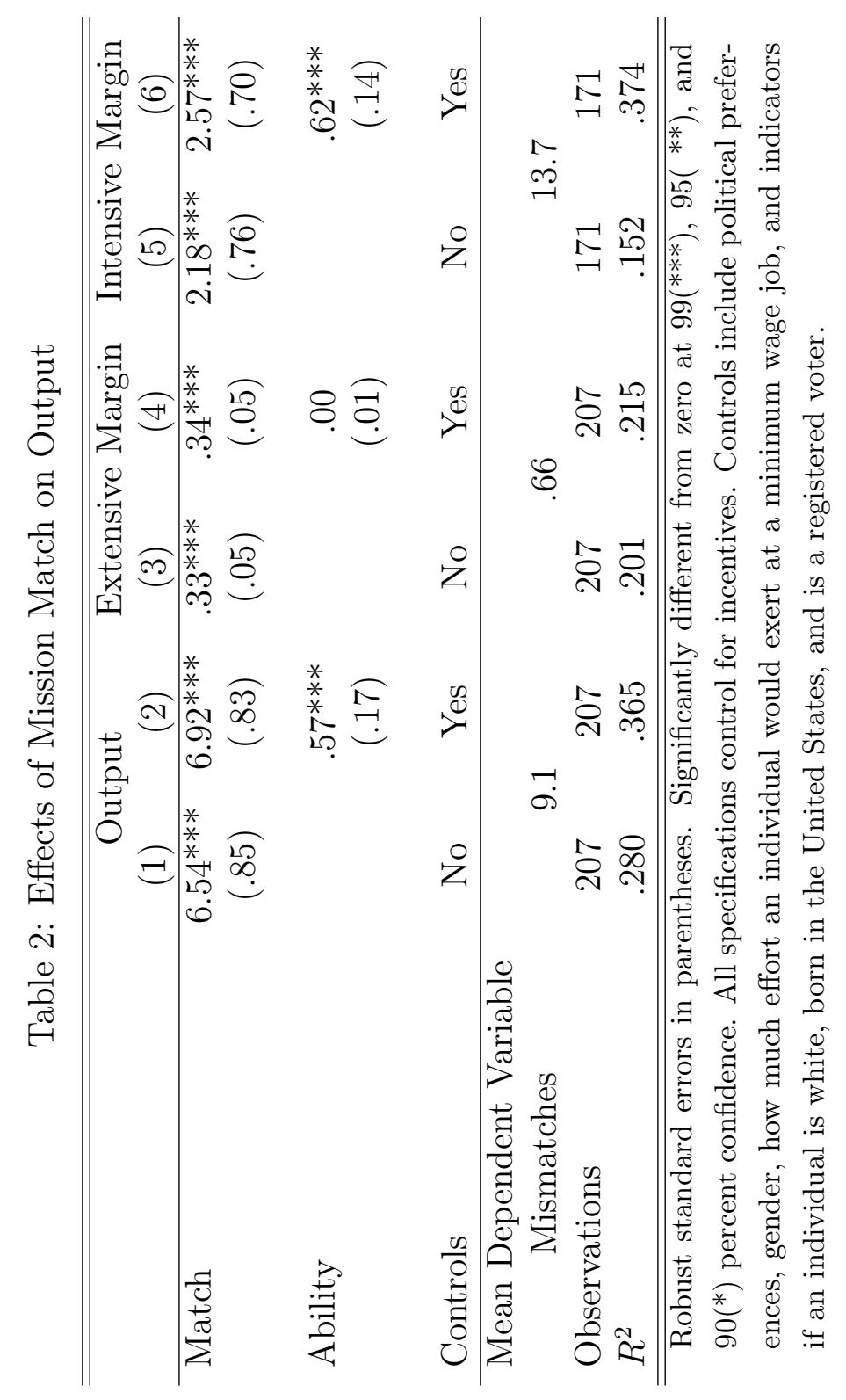




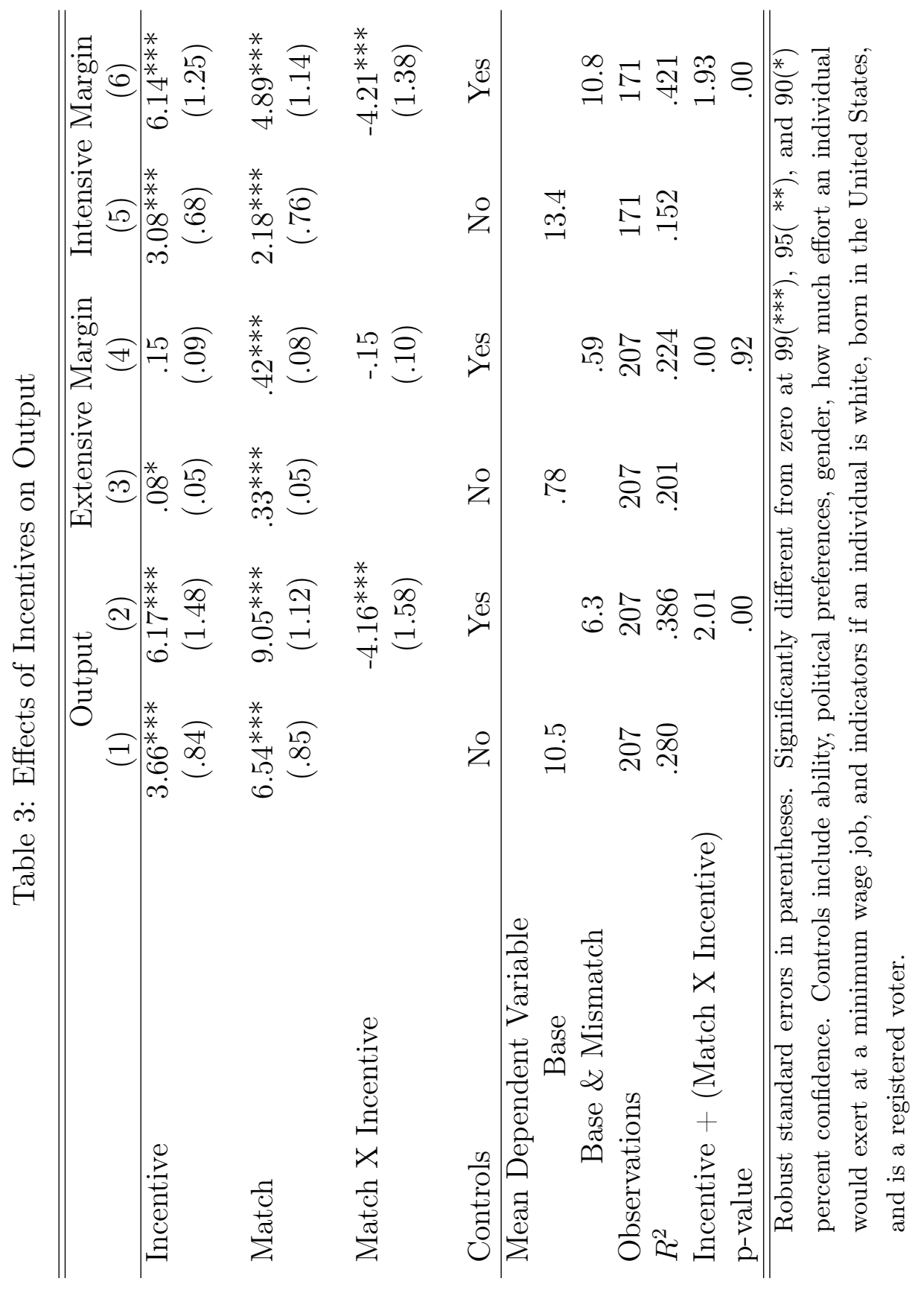




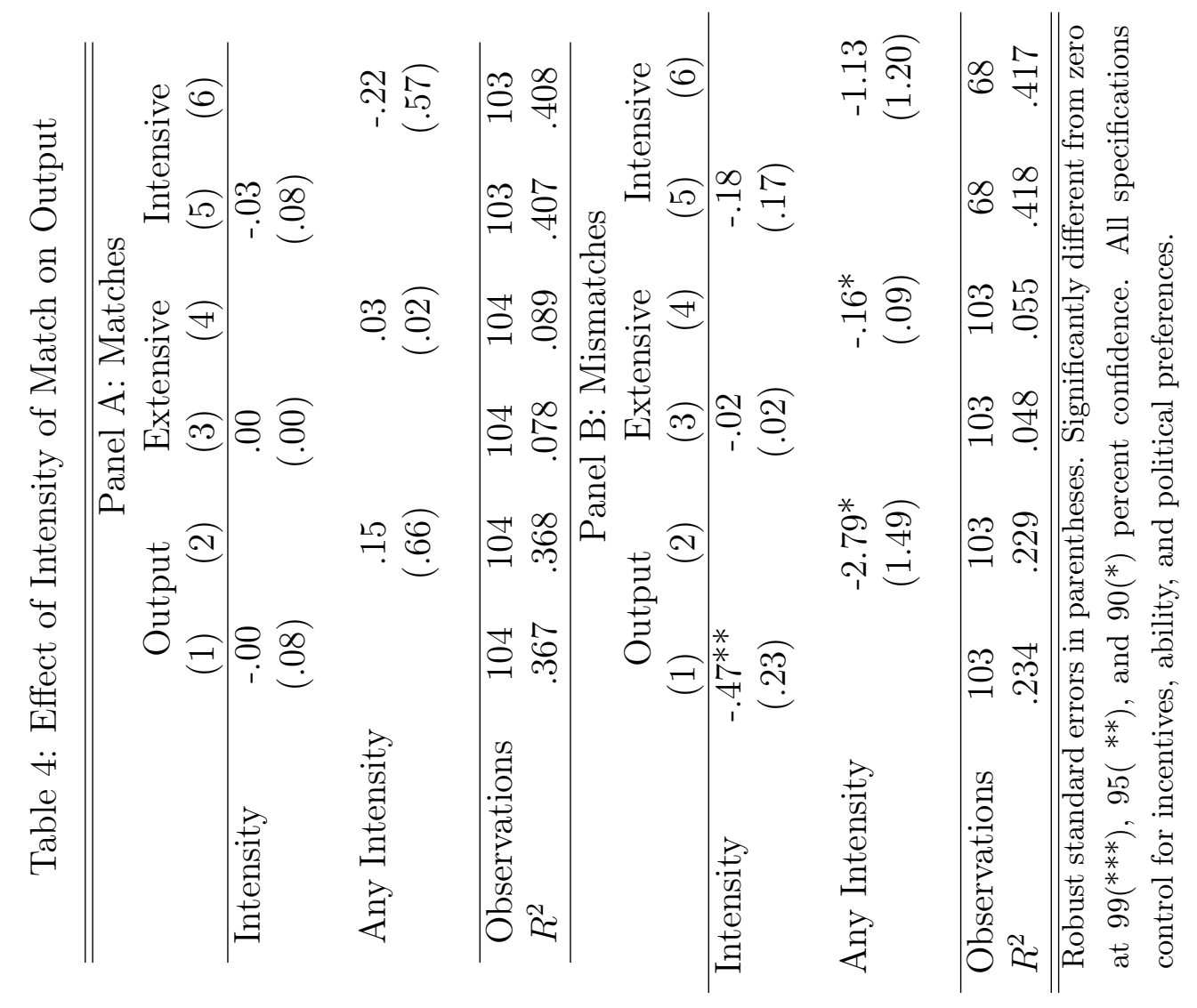




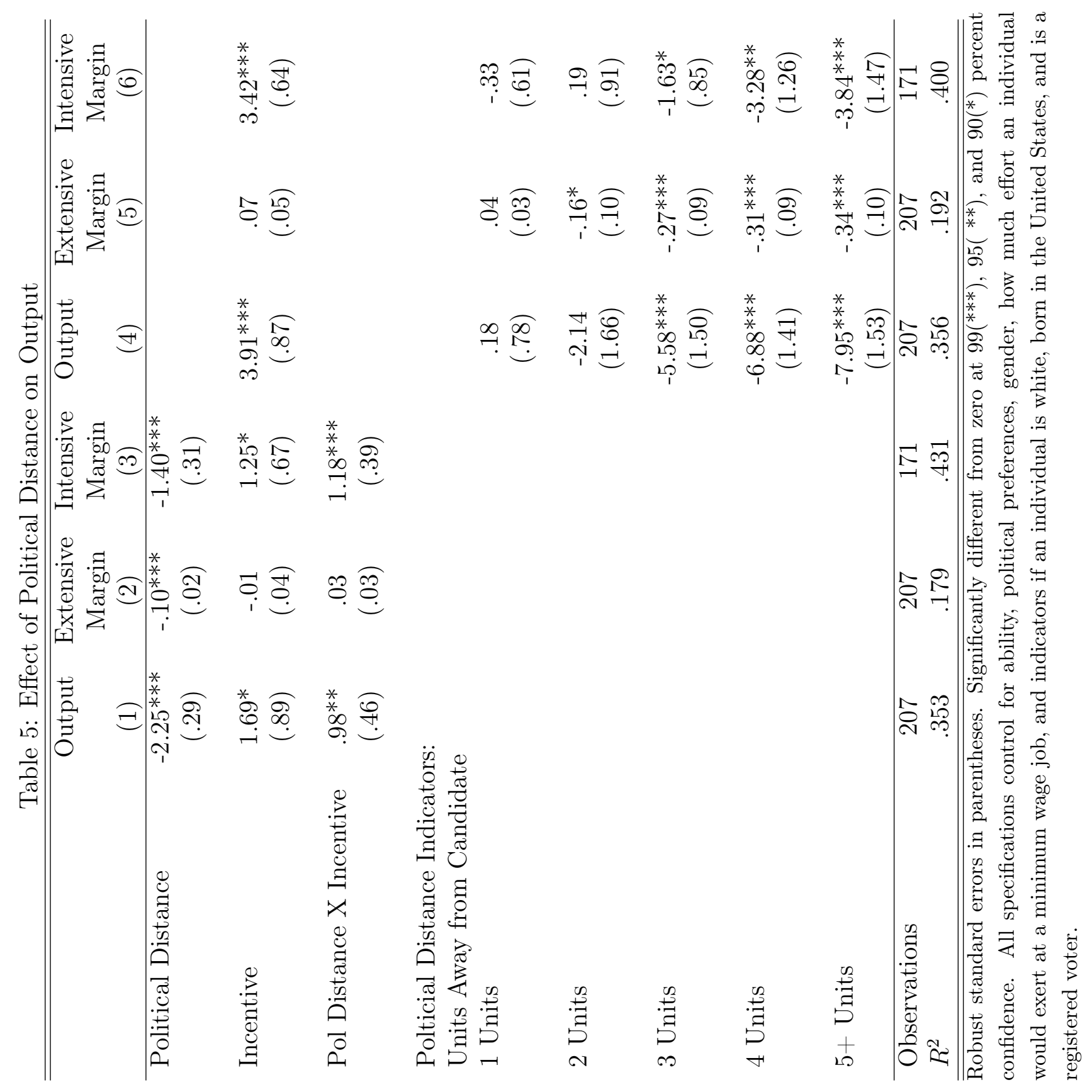




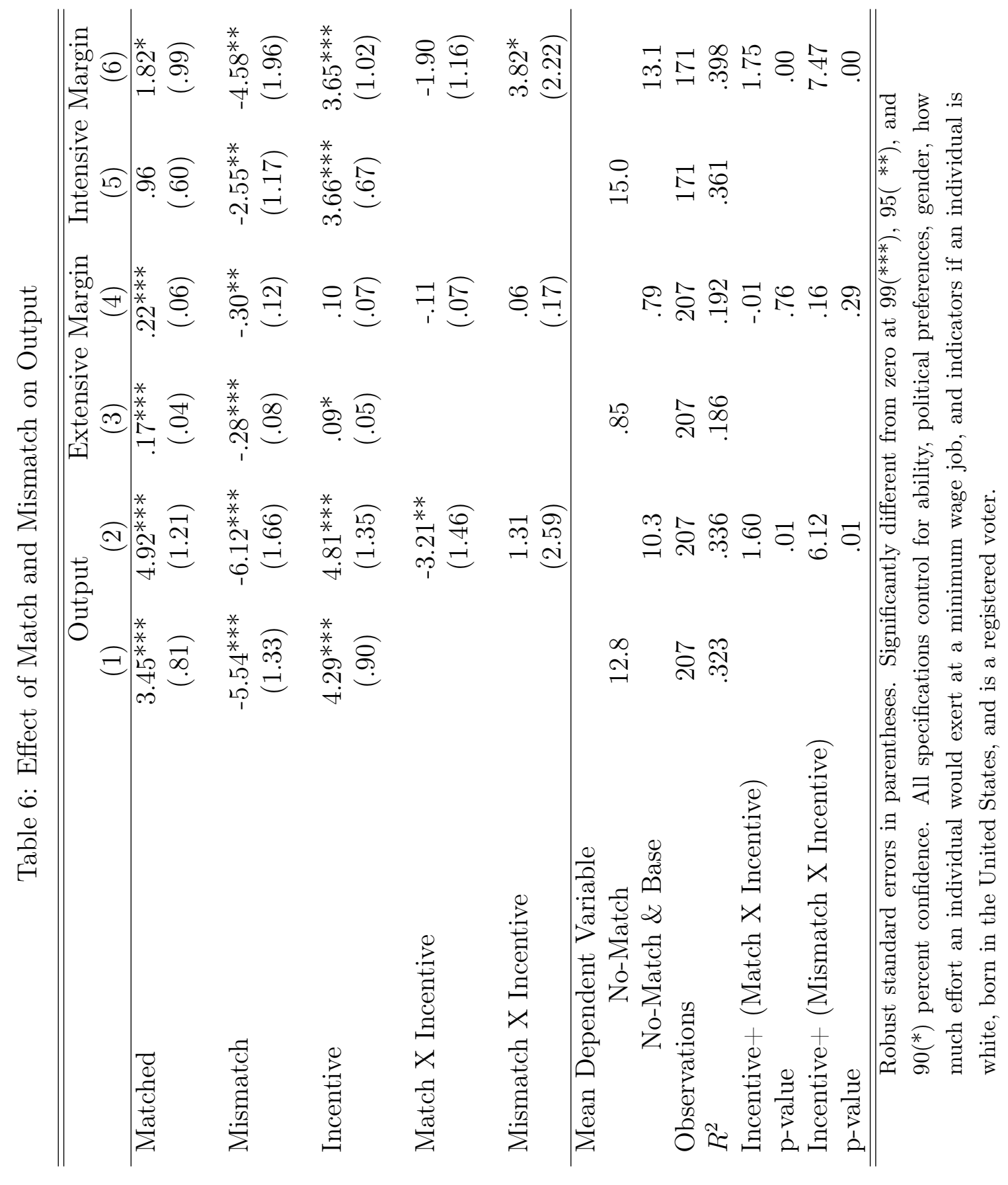




\section{A Appendix}

\section{A.1 Conceptual Framework}

An agent is offered a fixed wage $w$ and piece-rate $p$ and chooses $e^{*}$ to maximize her utility:

$$
U(e)=(w+p e)+\theta M(e, \gamma)-C(e)
$$

where the cost of effort $C(e)$ is increasing in effort $\left(C_{e}>0\right)$ and convex $\left(C_{e e}>0\right)$. Agents who match on mission preferences with the principal have $\theta=1$, while agents who are mismatched have $\theta=-1$. The utility an agent gets from an alignment (misalignment) of mission preferences is captured by a "mission utility" term $(M(e, \gamma))$. We allow for differences in the intensity of mission preferences, denoted as $\gamma \geq 0$; agents who strongly believe in a mission will get more utility from being matched compared to agents who have weaker preferences for the mission. Mission utility is increasing in effort at a diminishing rate $\left(M_{e}>0, M_{e e}<0\right)$ and is increasing in intensity $\left(M_{\gamma}>0\right)$. Lastly, $\gamma=0 \Rightarrow M(e, \gamma)=0$, the standard principal-agent formulation.

Agents have an outside option that generates a reservation utility of $\bar{U}$. We assume a continuous distribution of reservation utilities, and that principals do not know an agent's reservation utility before offering a contract. Since our focus is on the agent, the principal makes a single offer, and the agent works if $U\left(e^{*}\right)>\bar{U}$.

\section{The Effect of Matching}

The effect of mission match on effort can be seen by comparing the following:

$$
\begin{gathered}
e_{\theta=1}^{*}=\arg \max \{(w+p e)+M(e, \gamma)-C(e)\} \\
e_{\theta=-1}^{*}=\arg \max \{(w+p e)-M(e, \gamma)-C(e)\}
\end{gathered}
$$

Since the utility function is additively separable and $M_{e}>0$ then is must be the case that $e_{\theta=1}^{*}>e_{\theta=-1}^{*}$ or that agents exert more effort when they are mission matched. Since mission matching leads to greater utility $\left(U\left(e_{\theta=1}^{*}\right) \geq U\left(e_{\theta=-1}^{*}\right)\right)$ and distribu- 
tion functions are monotonic and nondecreasing, then matching increases the probability of an agent participating:

$$
P\left(\bar{U} \leq U\left(e_{\theta=1}^{*}\right)\right) \geq P\left(\bar{U} \leq U\left(e_{\theta=-1}^{*}\right)\right)
$$

\section{The Effect of Incentives}

The effect of increasing incentive pay on effort is:

$$
\frac{d e^{*}}{d p}=-\left(\frac{1}{\theta M_{e e}-C_{e e}}\right)
$$

which is positive $\left(\frac{d e^{*}}{d p}>0\right)$ for both matches and mismatches given the second order condition $\left(\theta M_{e e}-C_{e e}<0\right)$ at $e^{*}$. The effect of incentives is stronger in mismatches since $\left|M_{e e}-C_{e e}\right|>\left|-M_{e e}-C_{e e}\right|$ which implies that $\frac{d e^{*}(\theta=-1)}{d p}>\frac{d e^{*}(\theta=1)}{d p}$. Increasing incentives $(p)$ also leads to greater utility $\left(\frac{d\left(U\left(e^{*}\right)\right)}{d p} \geq 0\right)$, which implies that the probability of participating is increasing in $p$ :

$$
\frac{d P\left(\bar{U} \leq U\left(e^{*}\right)\right)}{d p}>0
$$

and incentives have a stronger effect on the participation of mismatches than matches:

$$
\frac{d \mathbb{P}\left(\bar{U} \leq\left(b e^{*}+w\right)-M\left(e^{*}, \gamma\right)-C\left(e^{*}\right)\right)}{d p} \geq \frac{d \mathbb{P}\left(\bar{U} \leq\left(b e^{*}+w\right)+M\left(e^{*}, \gamma\right)-C\left(e^{*}\right)\right)}{d p}
$$

\section{The Intensity of Preferences}

The effect of the intensity of mission preferences on effort is:

$$
\frac{d e^{*}}{d \gamma}=-\left(\frac{\theta M_{e \gamma}}{\theta M_{e e}-C_{e e}}\right)
$$

When the agent is matched $(\theta=1)$, then $\frac{d e^{*}}{d \gamma}>0$ since $M_{e \gamma}>0$. When there is a mismatch $(\theta=-1), \frac{d e^{*}}{d \gamma}<0$ because the second order condition implies $C_{e e}>\theta M_{e e}$. Therefore intense mission preferences increase effort in the case of a match, but lead to reduced effort when the agent is mismatched. For matches $(\theta=1)$, increases in the intensity of preferences leads to higher mission utility $\left(M_{\gamma} \geq 0\right)$ and overall utility 


$$
\begin{aligned}
&\left(\frac{d U\left(e_{\theta=1}^{*}\right)}{d \gamma} \geq 0\right) \text { which implies: } \\
& \qquad \frac{d P\left(\bar{U} \leq U\left(e_{\theta=1}^{*}\right)\right)}{d \gamma} \geq 0
\end{aligned}
$$

or that increasing preferences leads to an increase in the probability of participation for matches.

For mismatches $(\theta=-1)$, greater intensity leads to lower utility $\left(\frac{d U\left(e_{\theta=-1}^{*}\right)}{d \gamma}<0\right)$ which lowers the probability of participation

$$
\frac{d P\left(\bar{U} \leq U\left(e_{\theta=-1}^{*}\right)\right)}{d \gamma}<0 .
$$

\section{No-Matches}

No-matches are defined as those workers with no mission preferences (i.e., $\gamma=0$ ). For no-matches, the optimal level of effort is:

$$
e_{\gamma=0}^{*}=\arg \max \{(w+p e)-C(e)\} .
$$

Comparing this to equations 5 and 6 , we see that $e_{\theta=1}^{*}>e_{\gamma=0}^{*}>e_{\theta=-1}^{*}$ and that $\left(U\left(e_{\theta=1}^{*}\right) \geq U\left(e_{\gamma=0}^{*}\right) \geq U\left(e_{\theta=-1}^{*}\right)\right)$ which implies that matches have the greatest likelihood of satisfying the participation constraint, followed by no-matches, and then mismatches:

$$
P\left(\bar{U} \leq U\left(e_{\theta=1}^{*}\right)\right)>P\left(\bar{U} \leq U\left(e_{\gamma=0}^{*}\right)\right)>P\left(\bar{U} \leq U\left(e_{\theta=-1}^{*}\right)\right)
$$

The effect of increasing incentive pay on effort for no-matches is:

$$
\frac{d e^{*}}{d p}=-\left(\frac{1}{-C_{e e}}\right)
$$

where $\frac{d e^{*}}{d b}>0$ due to the second order condition. Comparing this comparative static to (7), and since $\left|M_{e e}-C_{e e}\right|>\left|-C_{e e}\right|>\left|-M_{e e}-C_{e e}\right|$, the effect of incentives on effort is strongest for mismatches, followed by no-matches, and then matches $\frac{d e^{*}(\theta=-1)}{d p}>\frac{d e^{*}(\gamma=0)}{d p}>\frac{d e^{*}(\theta=1)}{d p}$. As before, incentives have the strongest effect on satisfying the participation constraint for mismatches, followed by no-matches, and then 
matches:

$$
\begin{aligned}
& \frac{d \mathbb{P}\left(\bar{U} \leq\left(w+p e^{*}\right)-M\left(e^{*}, \gamma\right)-C\left(e^{*}\right)\right)}{d p}>\frac{d \mathbb{P}\left(\bar{U} \leq\left(w+p e^{*}\right)-C\left(e^{*}\right)\right)}{d p} \\
& \frac{d \mathbb{P}\left(\bar{U} \leq\left(w+p e^{*}\right)-C\left(e^{*}\right)\right)}{d p}>\frac{d \mathbb{P}\left(\bar{U} \leq\left(w+p e^{*}\right)+M\left(e^{*}, \gamma\right)-C\left(e^{*}\right)\right)}{d p}
\end{aligned}
$$




\section{A.2 Political Preferences}

The distribution of political preferences for the entire sample of survey respondents is presented on the left of Figure A.6. As mentioned in the main text, the campus skews Democrat but there are some Republicans $\left(n_{\text {Republican }}=111, n_{\text {Democrat }}=608\right.$, $\left.n_{\text {Independent }}=116\right)$. The distribution of preferences of those who actually participated in the experiment is shown on the right side of Figure A.6. Notice that, except for the missing independents, the two distributions look similar indicating that we managed to recruit a random draw from the survey population.

Figure A.6: The Distribution of Political Preferences
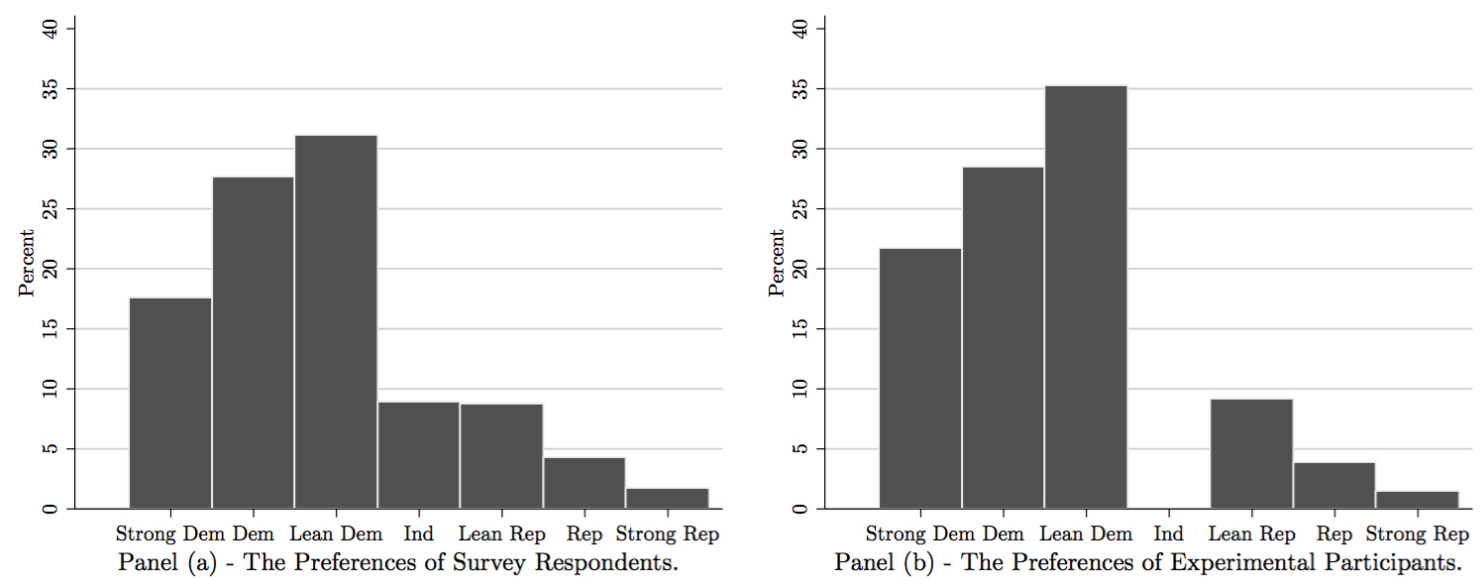

In Table A.6, we regress each policy statement taken from the PEW research classification system on an indicator for whether a respondent is classified as a Democrat. Estimates and standard errors are presented in each row. Each row represents a separate regression. As one can see, our simple typology accurately and parsimoniously captures the policy differences between the major campaigns.

Considering the results of our preference intensity dictator game, $52 \%$ of people decided to keep all the money for themselves, $43 \%$ chose the Obama campaign and the remaining $5 \%$ chose the Romney campaign. The distributions of gifts to the campaigns, by candidate, appear in Figure A.7. Conditional on giving, respondents gave more on average to Obama $(\$ 58)$ than to Romney $(\$ 45)$ and the difference is significant $(\mathrm{p}<0.01)$. 
Table A.7: Pew Political Statements

\begin{tabular}{|c|c|c|}
\hline \multirow[t]{2}{*}{ Dependent Variable: Do you agree with the following statement? } & \multicolumn{2}{|c|}{ Democrat Indicator } \\
\hline & Coefficent & SE \\
\hline There needs to be stricter laws and regulations to protect the environment & & \\
\hline & $.23^{* * *}$ & $(.08)$ \\
\hline $\begin{array}{l}\text { The government should help more needy people even if it means going deeper in } \\
\text { debt }\end{array}$ & $.75^{* * *}$ & $(.06)$ \\
\hline $\begin{array}{l}\text { The growing number of newcomers from other countries threaten traditional } \\
\text { American customs and values }\end{array}$ & $-.29 * * *$ & $(.09)$ \\
\hline I never doubt the existence of God & $-.49^{* * *}$ & (.10) \\
\hline Business corporations make too much profit & $.67^{* * * *}$ & $(.05)$ \\
\hline Gays and lesbians should be allowed to marry legally & $.14^{* *}$ & $(.06)$ \\
\hline The government needs to do more to make health care affordable and accessible & $.56^{* * *}$ & (.09) \\
\hline One parent can bring up a child as well as two parents together & .09 & $(.10)$ \\
\hline Government regulation of business usually does more harm than good & $-.57^{* * *}$ & $(.09)$ \\
\hline Abortion should be illegal in all or most cases & $-.32^{* * * *}$ & (.09) \\
\hline Labor unions are necessary to protect the working person & $.50^{* * *}$ & (.09) \\
\hline Poor people have become too dependent on government assistance programs & $-.61^{* * *}$ & $(.07)$ \\
\hline $\begin{array}{l}\text { Robust standard errors in parentheses. Significantly different from zero at } 99\left(^{* *}\right. \\
\text { confidence. All specifiations control for gender, ethnicity, and indicators if born } \mathrm{i} \\
\text { voter. }\end{array}$ & $\begin{array}{l}(* *), \text { and } \\
\text { US and if }\end{array}$ & $\begin{array}{l}\text { percen } \\
\text { stered }\end{array}$ \\
\hline
\end{tabular}


Figure A.7: Political Dictator Game Results
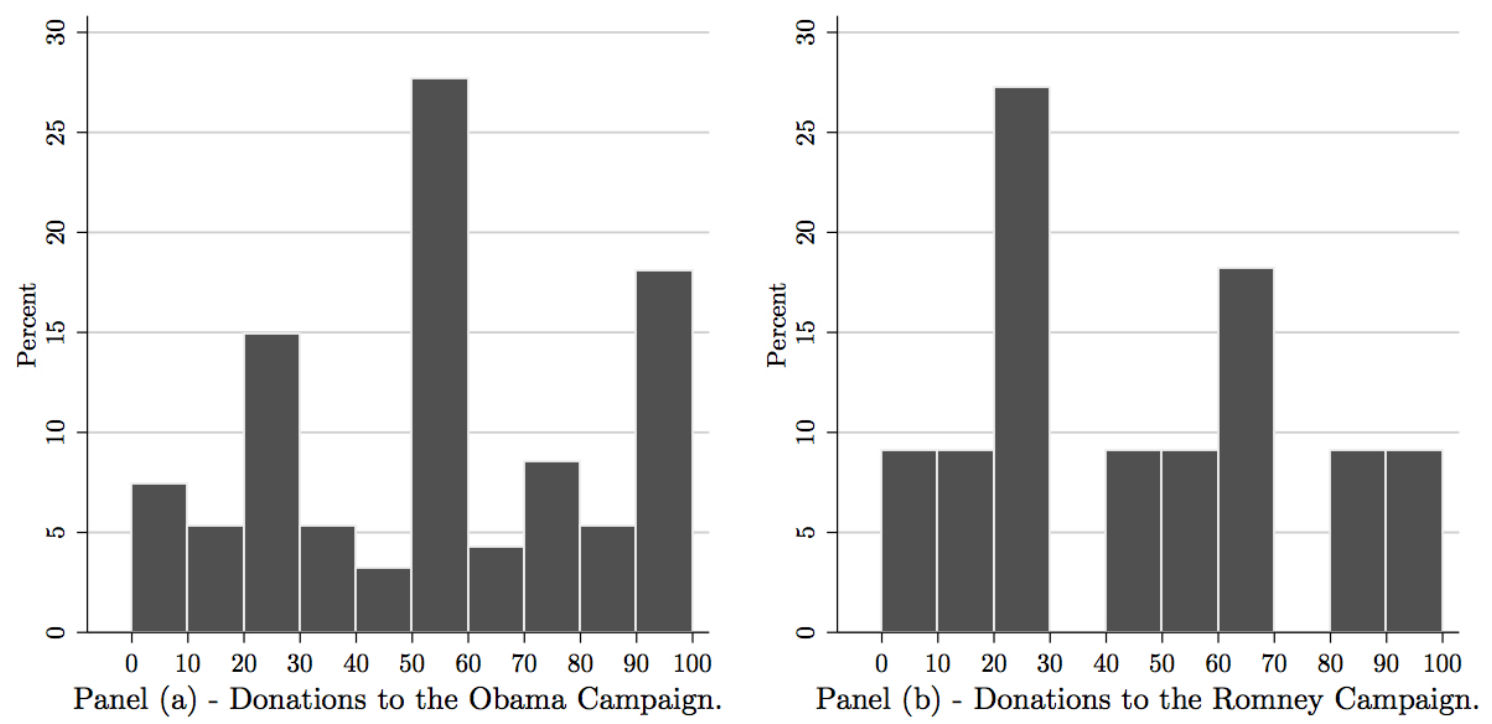


\section{A.3 Study Instructions}

\section{Experiment Instructions}

Introduction

Today you will participate in a letter production experiment that has two parts. For your participation today you will paid, in cash, at the end of the experiment. Three study participants will be random chosen to receive $\$ 30$ delivered to their mailbox by the end of the semester. Please do not speak to any of the other participants until the session is completed and do not speak to people outside today's session until our entire experiment has concluded at the end of October.

We have gone to great lengths to make sure that your participation today will be anonymous - any identifiers will be removed as soon as the data has been collected.

Instructions for Part 1

In part 1 of the experiment you will be completing a production task that consists of:

- Filling in the recipient's first name on letters addressed to friends of Middlebury College. A mailing list is provided for you.

- Folding and putting the letters in envelopes.

- Sealing and hand-addressing the envelopes. Although your performance in this task will not affect the amount of money you earn today, it is important that you complete this task in good faith - we are curious to know how many letters you can complete in 15 minutes. After the experimenter demonstrates how the tasks should be completed, you will begin Part 1. Are there any questions? 
Instructions for Part 2

In the second part of the experiment you will be doing a very similar letter production task to that in Part 1: you will address, stuff and complete letters. However, there are a few important differences between the two parts of the experiment. In Part 2:

- You will have 15 minutes to produce as many letters as you like. How hard you work is completely up to you. As a reminder, please do not speak to any participants until the session is complete.

- The letters that you will be completing are campaign letters for one of the two major party Presidential candidates.

- The recipients of the letters are independent voters in Hamilton County, Ohio, which is a contested country in an important swing state in the election. Once our experiment is completed, the letters will be stamped and mailed in October. Since the letters will be mailed to actual voters, it is important that they are done correctly with the names matching the addresses given.

- The presidential candidate for whom you will work has been randomly determined. Everyone in the session today will work for only one candidate (Obama or Romney) and to assure that the assignment was done by chance, the manila packets were randomly assigned to each of you before the session began.

- You will be compensated for your work in Part 2. Specifically, you will receive a base wage of $\$ 20$ plus an additional 50 cents for each letter you complete during the 15 minutes. This payment will be made after the experiment is completed.

Again, we have gone to great lengths to make sure that your participation today will be anonymous - any identifiers will be removed as soon as the data has been collected.

After the experimenter reminds you how the tasks should be completed, you will begin Part 2. Are there any questions? 


\section{A.4 Robustness}

Table A.8: Alternative Matching Classifications

\begin{tabular}{lcccccc}
\hline \hline & \multicolumn{2}{c}{ Output } & \multicolumn{2}{c}{ Extensive Margin } & \multicolumn{2}{c}{ Intensive Margin } \\
& $(1)$ & $(2)$ & $(3)$ & $(4)$ & $(5)$ & $(6)$ \\
\hline Match (Voting Pref) & $6.89^{* * *}$ & \multicolumn{3}{c}{$.34^{* * *}$} & \multicolumn{3}{c}{$2.55^{* * *}$} \\
& $(.83)$ & \multicolumn{3}{c}{$(.05)$} & & $(.71)$ \\
Match (Party Registration) & & $5.22^{* * *}$ & & $.25^{* * *}$ & & $1.77^{* *}$ \\
& & $(.97)$ & & $(.05)$ & & $(.71)$ \\
Ability & & & & & & \\
& $.56^{* * *}$ & $.40^{* *}$ & .00 & -.01 & $.62^{* * *}$ & $.55^{* * *}$ \\
& $(.17)$ & $(.20)$ & $(.01)$ & $(.01)$ & $(.14)$ & $(.15)$ \\
\hline Observations & & & & & & \\
$R^{2}$ & 207 & 207 & 207 & 207 & 171 & 171 \\
\hline \hline
\end{tabular}

Robust standard errors in parentheses. Significantly different from zero at $99(* * *), 95\left({ }^{* *}\right)$, and $90\left(^{*}\right)$ percent confidence. All specifications control for ability, political preferences, gender, how much effort an individual would exert at a minimum wage job, and indicators if an individual is white, born in the United States, and is a registered voter. 
Table A.9: Clustering Standard Errors at Session Level

\begin{tabular}{lcccccc}
\hline \hline & \multicolumn{2}{c}{ Output } & \multicolumn{2}{c}{ Extensive Margin } & \multicolumn{2}{c}{ Intensive Margin } \\
& $(1)$ & $(2)$ & $(3)$ & $(4)$ & $(5)$ & $(6)$ \\
\hline Match & $6.54^{* * *}$ & $6.92^{* * *}$ & $.33^{* * *}$ & $.34^{* * *}$ & $2.18^{*}$ & $2.57^{* *}$ \\
& $(1.03)$ & $(1.00)$ & $(.04)$ & $(.04)$ & $(1.03)$ & $(1.03)$ \\
Ability & & $.57^{* * *}$ & & .00 & & $.62^{* * *}$ \\
& & $(.12)$ & & $(.01)$ & & $(.14)$ \\
Controls & & & & & & \\
\hline Observations & No & Yes & No & Yes & No & Yes \\
$R^{2}$ & .207 & 207 & 207 & 207 & 171 & 171 \\
\hline
\end{tabular}

Standard errors clustered at the session level in parentheses. Significantly different from zero at $99(* * *), 95(* *)$, and $90\left(^{*}\right)$ percent confidence. All specifications control for incentives. Controls include political preferences, gender, how much effort an individual would exert at a minimum wage job, and indicators if an individual is white, born in the United States, and is a registered voter.

Table A.10: Change in Output Between Production vs. Ability Rounds

\begin{tabular}{lcccccc}
\hline \hline & \multicolumn{2}{c}{$\begin{array}{c}\text { Change in } \\
\text { Output }\end{array}$} & \multicolumn{2}{c}{$\begin{array}{c}\text { Indicator if } \\
\text { Output Increased }\end{array}$} & \multicolumn{2}{c}{$\begin{array}{c}\text { Change in } \\
\text { Output Conditional } \\
\text { on Any Output } \\
\end{array}$} \\
& $\begin{array}{c}(1) \\
\text { Match }\end{array}$ & $(2)$ & $(3)$ & $(4)$ & $(5)$ & $(6)$ \\
& $\left(.01^{* * *}\right.$ & $7.02^{* * *}$ & $.34^{* * *}$ & $.35^{* * *}$ & $2.75^{* * *}$ & $2.67^{* * *}$ \\
& & $(.85)$ & $(.06)$ & $(.06)$ & $(.68)$ & $(.72)$ \\
Controls & No & Yes & No & Yes & No & Yes \\
\hline Observations & 207 & 207 & 207 & 207 & 171 & 171 \\
$R^{2}$ & .341 & .349 & .306 & .318 & .266 & .275 \\
\hline \hline
\end{tabular}

Robust standard errors in parentheses. Significantly different from zero at $\left.99{ }^{* * *}\right), 95\left(^{* *}\right)$, and $90\left(^{*}\right)$ percent confidence. All specifications control for incentives. Controls include political preferences, gender, how much effort an individual would exert at a minimum wage job, and indicators if an individual is white, born in the United States, and is a registered voter. 
Table A.11: Change in Output Between Production vs. Ability Rounds

\begin{tabular}{|c|c|c|c|c|c|c|}
\hline & \multicolumn{2}{|c|}{$\begin{array}{c}\text { Change in } \\
\text { Output }\end{array}$} & \multicolumn{2}{|c|}{$\begin{array}{c}\text { Indicator if } \\
\text { Output Increased }\end{array}$} & \multicolumn{2}{|c|}{$\begin{array}{c}\text { Change in } \\
\text { Output Conditional } \\
\text { on Any Output }\end{array}$} \\
\hline & (1) & (2) & (3) & (4) & (5) & (6) \\
\hline Incentive & $\begin{array}{c}4.54^{* * *} \\
(.82)\end{array}$ & $\begin{array}{c}6.62^{* * *} \\
(1.47)\end{array}$ & $\begin{array}{l}.43^{* * *} \\
(.06)\end{array}$ & $\begin{array}{l}.47^{* * *} \\
(.09)\end{array}$ & $\begin{array}{c}3.98^{* * * *} \\
(.62)\end{array}$ & $\begin{array}{c}6.56^{* * *} \\
(1.25)\end{array}$ \\
\hline Match & $\begin{array}{c}7.01^{* * *} \\
(.82)\end{array}$ & $\begin{array}{c}9.19^{* * *} \\
(1.17)\end{array}$ & $\begin{array}{l}.34^{* * *} \\
(.06)\end{array}$ & $\begin{array}{l}.40^{* * *} \\
(.09)\end{array}$ & $\begin{array}{c}2.75^{* * *} \\
(.68)\end{array}$ & $\begin{array}{c}5.03^{* * *} \\
(1.20)\end{array}$ \\
\hline Match X Incentive & & $\begin{array}{c}-4.22^{* * * *} \\
(1.62)\end{array}$ & & $\begin{array}{l}-.10 \\
(.12)\end{array}$ & & $\begin{array}{c}-4.28^{* * *} \\
(1.43)\end{array}$ \\
\hline Controls & No & Yes & No & Yes & No & Yes \\
\hline Observations & 207 & 207 & 207 & 207 & 171 & 171 \\
\hline$R^{2}$ & .341 & .370 & .306 & .320 & .266 & .327 \\
\hline Match+MatchXIncentive & & 2.40 & & .37 & & 2.28 \\
\hline p-value & & .00 & & .00 & & .00 \\
\hline
\end{tabular}

Robust standard errors in parentheses. Significantly different from zero at $99\left(^{* * *}\right), 95(* *)$, and $90(*)$ percent confidence. Controls include political preferences, gender, how much effort an individual would exert at a minimum wage job, and indicators if an individual is white, born in the United States, and is a registered voter. 
Table A.12: Piece Rate Incentives and Output

\begin{tabular}{|c|c|c|c|c|c|c|}
\hline & \multicolumn{2}{|c|}{$\overline{\text { Output }}$} & \multicolumn{2}{|c|}{ Extensive Margin } & \multicolumn{2}{|c|}{ Intensive Margin } \\
\hline & (1) & (2) & (3) & (4) & (5) & (6) \\
\hline Match & $\begin{array}{c}6.53^{* * *} \\
(.84)\end{array}$ & $\begin{array}{c}9.01^{* * *} \\
(1.13)\end{array}$ & $\begin{array}{l}.33^{* * *} \\
(.05)\end{array}$ & $\begin{array}{c}.41^{* * *} \\
(.08)\end{array}$ & $\begin{array}{c}2.19^{* * *} \\
(.76)\end{array}$ & $\begin{array}{c}4.92^{* * *} \\
(1.15)\end{array}$ \\
\hline$\$ 0.50$ Piece Rate & $\begin{array}{c}4.41^{* * *} \\
(.99)\end{array}$ & $\begin{array}{c}7.20^{* * *} \\
(1.69)\end{array}$ & $\begin{array}{l}.12^{* *} \\
(.05)\end{array}$ & $\begin{array}{l}.23^{* *} \\
(.10)\end{array}$ & $\begin{array}{c}3.23^{* * *} \\
(.78)\end{array}$ & $\begin{array}{c}5.69^{* * *} \\
(1.42)\end{array}$ \\
\hline$\$ 1.00$ Piece Rate & $\begin{array}{c}2.83^{* * *} \\
(1.08)\end{array}$ & $\begin{array}{c}5.00^{* *} \\
(2.06)\end{array}$ & $\begin{array}{c}.04 \\
(.06)\end{array}$ & $\begin{array}{c}.06 \\
(.12)\end{array}$ & $\begin{array}{c}2.90^{* * *} \\
(.81)\end{array}$ & $\begin{array}{c}6.82^{* * *} \\
(1.49)\end{array}$ \\
\hline Match X $\$ 0.50$ & & $\begin{array}{c}-5.20^{* * *} \\
(1.79)\end{array}$ & & $\begin{array}{c}-.23^{* *} \\
(.11)\end{array}$ & & $\begin{array}{c}-3.78^{* *} \\
(1.52)\end{array}$ \\
\hline Match X $\$ 1.00$ & & $\begin{array}{l}-2.92 \\
(2.15)\end{array}$ & & $\begin{array}{l}-.06 \\
(.12)\end{array}$ & & $\begin{array}{c}-4.89^{* * *} \\
(1.64)\end{array}$ \\
\hline Controls & No & Yes & No & Yes & No & Yes \\
\hline Observation & 207 & 207 & 207 & 207 & 171 & 171 \\
\hline$R^{2}$ & .286 & .392 & 208 & .235 & 153 & .424 \\
\hline
\end{tabular}

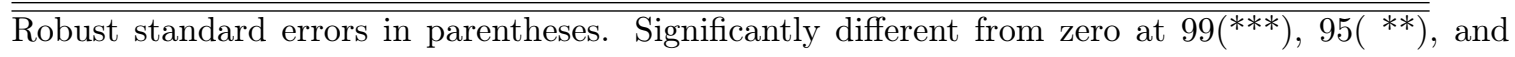
$90\left(^{*}\right)$ percent confidence. Controls include ability, political preferences, gender, how much effort an individual would exert at a minimum wage job, and indicators if an individual is white, born in the United States, and is a registered voter. 


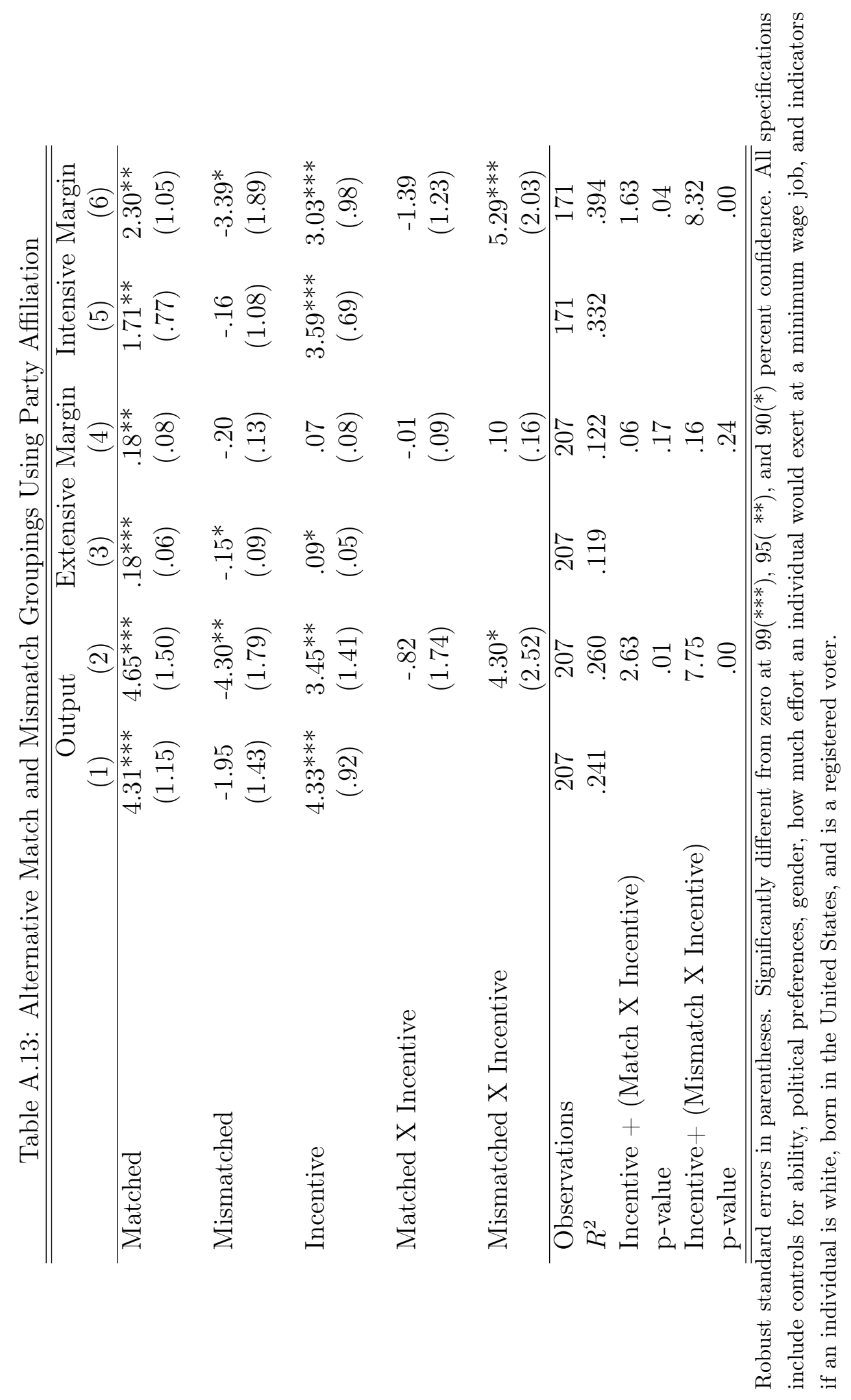

